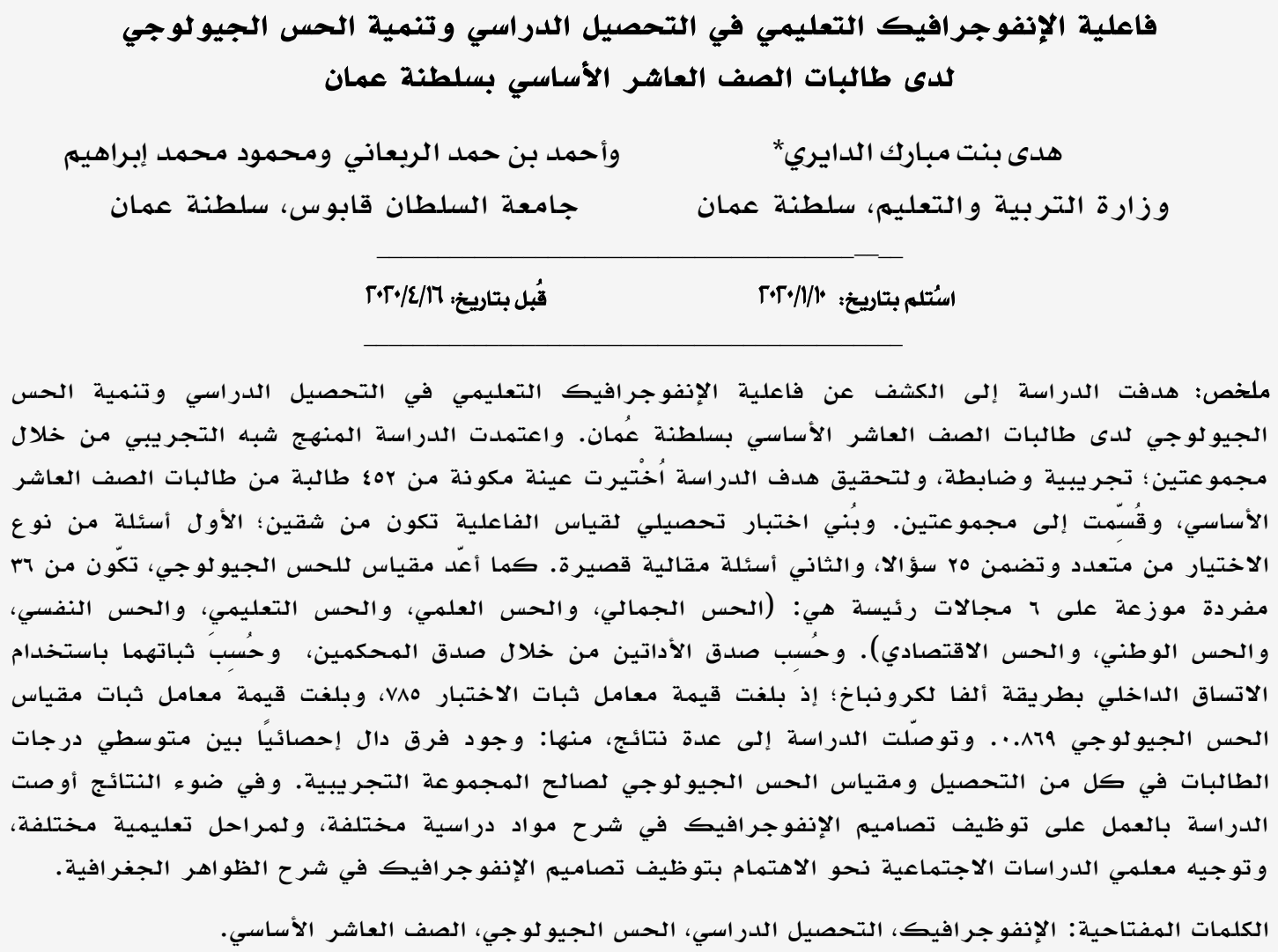

The Effectiveness of Educational Infographics in the Academic Achievement and Geological Sense Development among Tenth Grade Students in the Sultanate of Oman

Huda M. Al-Dayri*,

Ministry of Education, Sultanate of Oman
Ahmed H. Al-Rabaani \& Mahmoud M. Ibrahim Sultan Qaboos University, Sultanate of Oman

Abstract: This study aimed to investigate the effectiveness of educational infographics in the academic achievement and the development of geological sense among tenth grade students in the Sultanate of Oman. To achieve the goals of the study, a sample of 452 female students from grade ten were chosen. They were divided into two groups. The effectiveness of infographics was measured by building an achievement test consisting of 25 single-type multiple choice items, and short essay questions. Likewise, a measure of geological sense was prepared, which consisted of 36 items distributed in 6 main categories: (the aesthetic sense, the scientific sense, the educational sense, the psychological sense, the national sense, and the economic sense). The validity of the two tools was verified by presenting them to 20 arbitrators. Their consistency was calculated using the internal consistency by the Cronbach alpha method, where the value of the stability coefficient in the test was 0.785 , and the stability of the geological sense scale was 0.869 . The results of the study indicated that there is a statistically significant difference between the female students' scores in both the achievement and the geological sense scale for the benefit of the experimental group. In light of the results, the study recommended activating the use of infographics in the teaching of geographical issues and spreading a culture of its use.

Keywords: Infographics, academic achievement, geological sense, basic tenth grade.

*s36157@student.squ.edu.om 
و يعمل الإنفوجر افيك على تنميـة الههارات

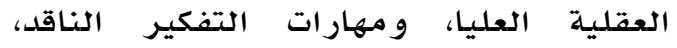

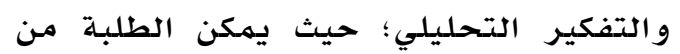

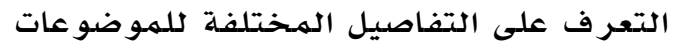

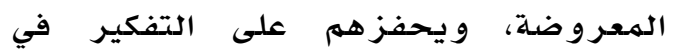
كافة الجوانب ذات الصلة بالهوضوضوع، وينهمي لديهم الحس الفني للتعبير عن أفكارهم

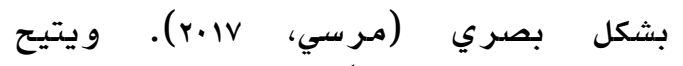

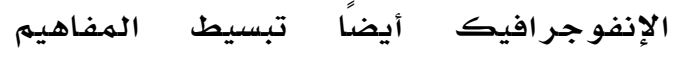
المجرردة والمعقدة للطلبة ؛ مما يسهل عليهم (Holmquist, Holmberg \& فهمها و هذه .Hosanona, 2009; Ozturk, 2002) العملية تؤدي إلى تعزيز قدرة الطلبة على

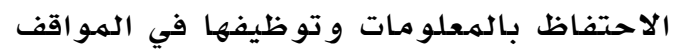

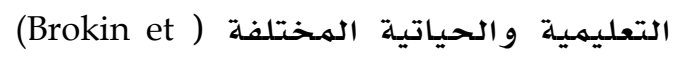

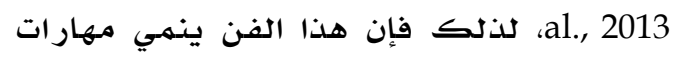

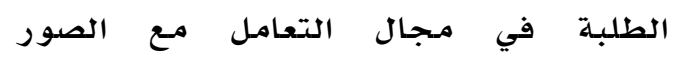

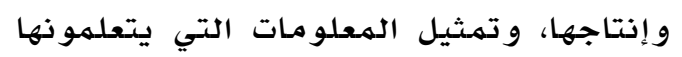

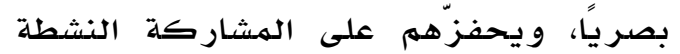

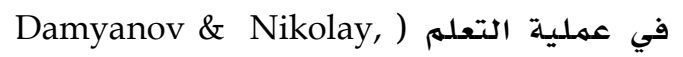

وهذه الهميزات تجعل الإنفوجر افيك مـلائماً

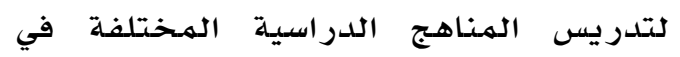

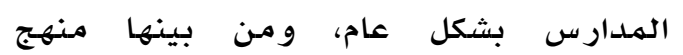
الدراسات الاجتماعية على وجهـ الخصوص لته التي تحتوي على موضوعات كثيرة تتضمن

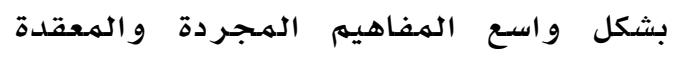

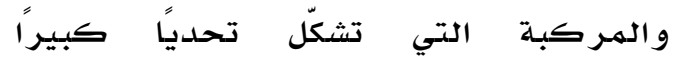

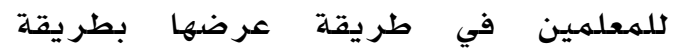
مبسطة، وكذلك للطلبة الذين يواجهون

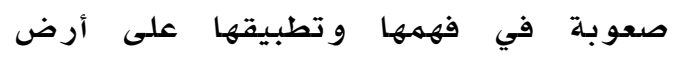

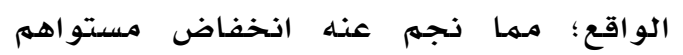

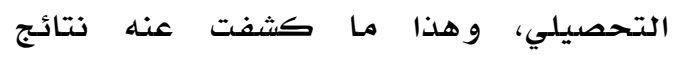

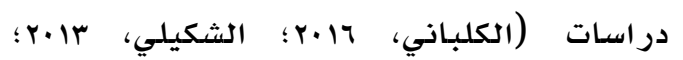

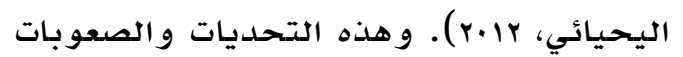

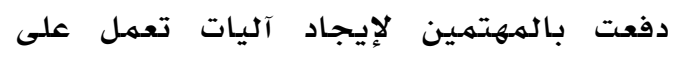

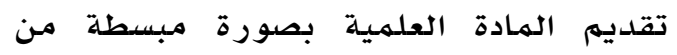

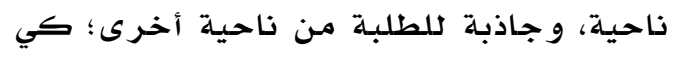

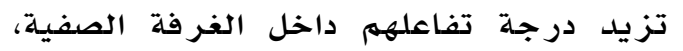

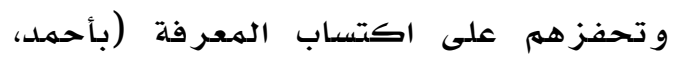

يُعد التطور التكنولوجي من العوامل التي إتي

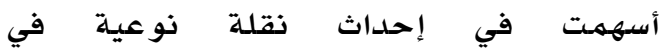
الإنفوجر افيك؛ مها جعله يلقى شهرة واسعة استة

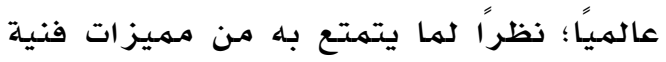
لعرض الأفكار بشكل مصور تمتاز بالجاذبية

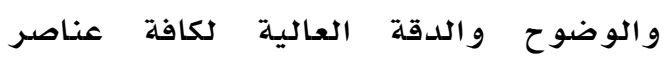
الموضو والو صوح ع المستهدف.

و يعرف الإنفوجر افيك على أنه "فن تحويل

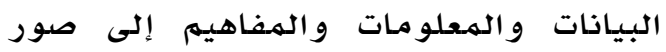

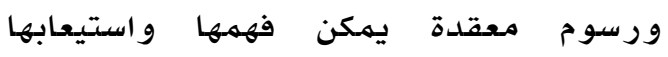

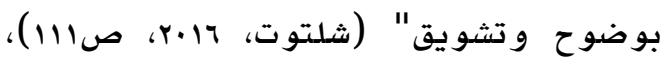

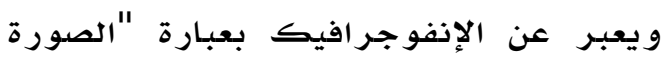

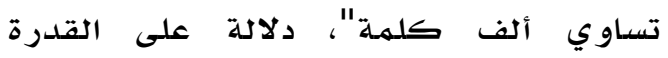
الفائقة في اختزال الأشياء وتقديمهـ بصورة

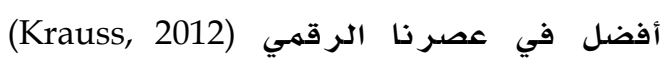

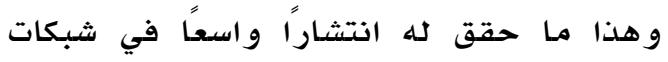

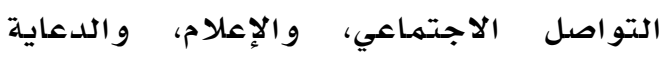

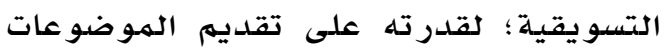
عبر صور تتصف بالجاذبية لكافة الفئات

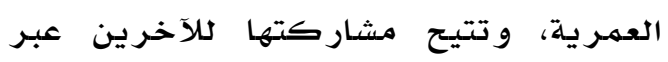

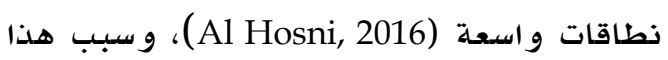
الانتشار ينطلق من كوذنه يركز على حاسـة

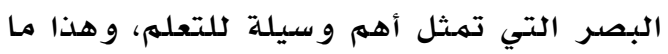

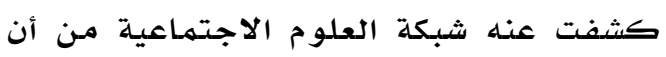

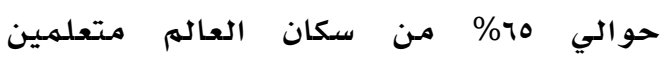
بصريين (McCue, 2013). حيث أن ما مي بين

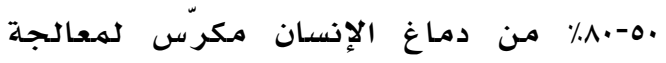

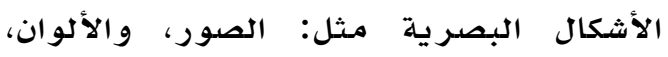
و الحر كة (Justin Beegel, 2014).

و تشير الأدبيات إلى أن بداية افهور

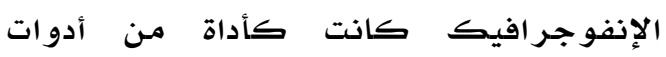

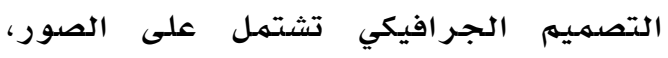

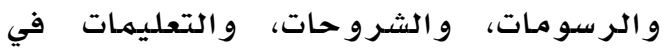

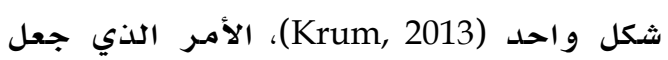

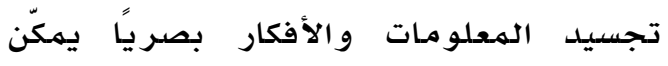

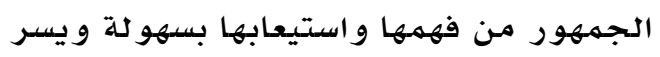

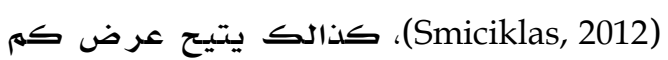
هائل من الصور بسرعة عالية بطريقة توضح التسلسل الزمني لكلأحداث و الظواهر

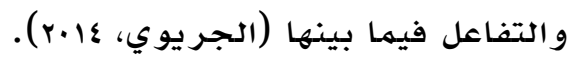


بالعديد من المقومات الجمالية المتمثلة في

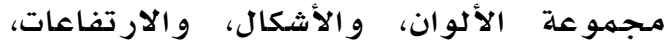

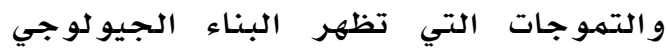

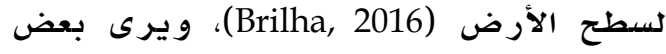
الباحثين أن الاهتمام بالحس الجيو لوجي له له

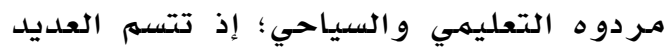
من المعالم الجيول لوجية بجمال خلاب تدفع

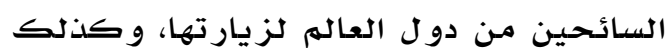

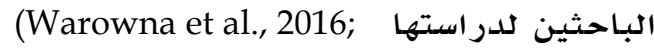
، ومن Kirillova, Fu, Lehto \&Cai, 2014) خلال زيارة هذه المعالهم يدرك الطلبة قدرة

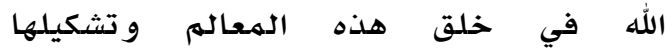
.(Kirillova et al., 2014)

مشكلة الدراسة

تُعد قضية التحصيل الدراسي مـن القضايا التي تؤرق القائمين على النظام التعليمي؛ فالمؤسسات التعليمية تنفق موازنات ضوريمة الهمية

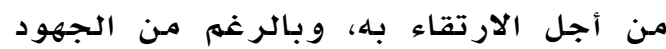

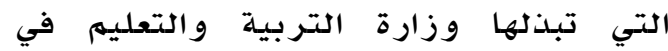
سلطنة عمان في تطوير المناهج الدراسية، ورفع كفاءة المعلمين، لا لات تزال نتائج

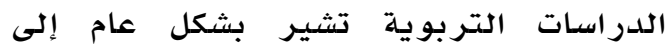

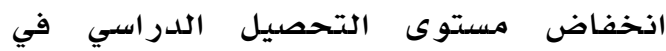

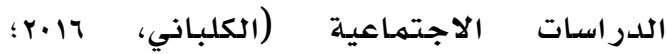

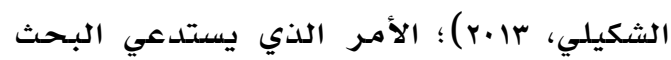

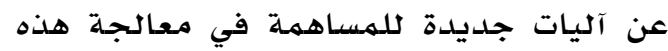
المشكلة من خلال الاستفادة مهما أنتجته الثورة الرقمية من تقنيات وأدوات متتنوعة

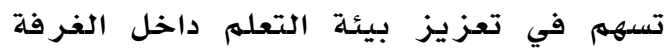
الصفية، و في الوقت ذاته تتناسب مـع طريقة

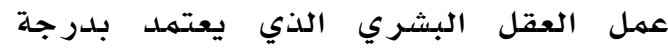

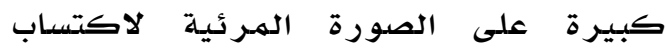

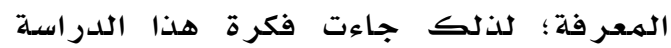
لتطبيق الإنفوجر افيك في مادة الدرراسات

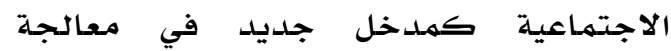

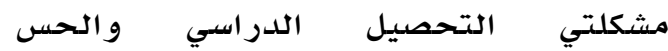
الجيو لوجي.

وبالإضافة إلى ذلك، تتجّه الأنظمهة التربوية والأجيال الحالية بشكل كبير نحو توظيف

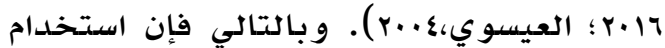
الإنفوجر افيك يمثل أحد الأدوات التي قدي

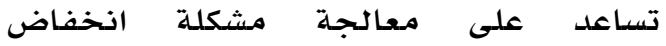
التحصيل الدراسي في الدراسات الاجتماعية؛ حيث كشفت نتائج بعض الدراسات عن فاعليته في تنمية التحصيل في بعض المواد

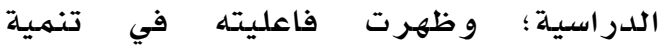

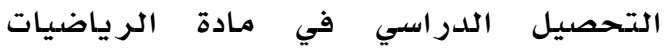

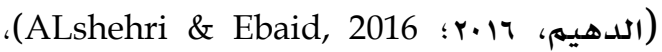
و فاعليته في تعزيز التحصيل في مادة اللغة

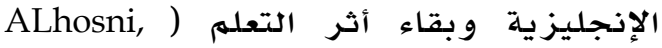

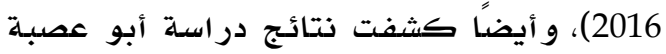

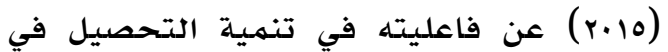

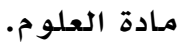

و بالإضـافة إلى مشكلة التحصيل الدراسي في مـادة الدراسات الاجتماعية التي يواجهها

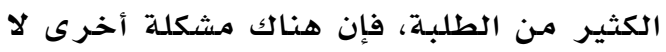

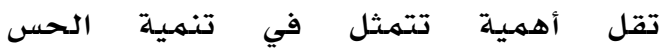
الجيولوجي لديهم، وهو أحد العناصر الرئيسة التي يتطلب تنهيتها لدى الطى الطلبة؛ نظرًا لقلة اهتمام الباحثين بها في في مادة

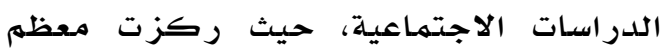
الدراسات على القضايا السياسية والاقتصـادية الاسية و الاجتماعية و البيئية و التاريخية. و يعرف الحس الجيولوجي بأنه: "إحساس

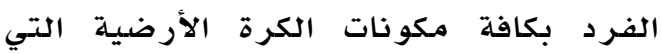
يتفاعل معها بشكل يومي تأثرًا و تأثيرًا،

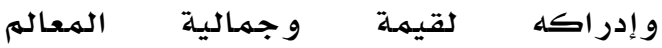
الجيو لوجية على سطح الأرض التي يتفاعل معها" (Clary \& Wandersee, 2006, p.52) و من خلال التعريف تتضـح أهمية إبراز القيهم

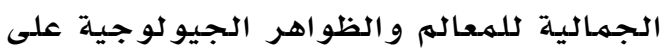
سطح الأرض، فلا يُكتفى فقط بلدراستها من حيث خصائصها و أشكالها، بل إظهار الأبعاد

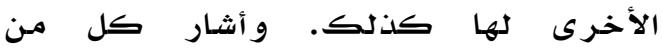
(Ruban, 2015; Dowling, 2011) تعزيز الحس الجمالي للهمحاله الجيولوجية الجية

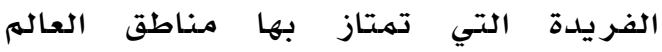

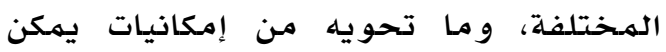

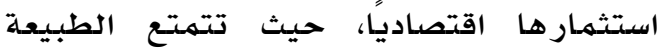


أسئلة الدر اسة

ا. ما اعلية استخدام الإنفوجرافيك التعليمي في التحصيل الدراسي للدى الإنفوجيافي

طالبات الصف العاشر الأساسي بسلطنة

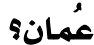

r. ما ماعلية استخدام الإنفوجرافيك

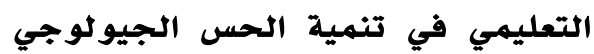

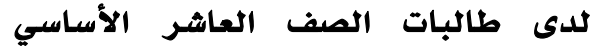

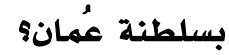

فر ضيات الدراسة

في ضوء الأسئلة الســابقة للدراســة، صـيغت الفر ضيات الصفرية الآتية:

ا. لا توجد فـروق ذات دلالـة إحصـائية

عند مستوى ل

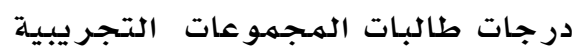

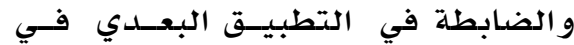

التحصيل الدر اسي.

r r لا توجد فـروق ذات دلاصـة إحصـائية

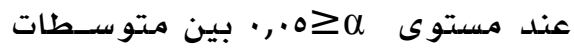

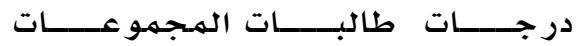

التجريبية و الضـابطة في التطبيـق

البعدي في الحس الجيولوجي.

أهداف الدراسة

1. الكثـف عـن مــدى فاعليسة اسـتخدام

الإنفوجر افيك التعليمي في التحصيل

الدراسي لدى طالبــات الصـف العاشــر

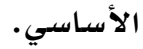

r. التعرف على درجسة فاعليـة اسـتخدام

الإنفوجر افيك التعليمسي فسي تنميسة

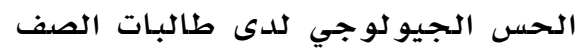

العاشر الأساسي.

أهمية الدراسة

تتمثل أهمية الدراسـة في:

1. تقديم أنموذج عملي لتوظيف تصاميه

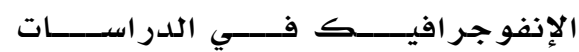

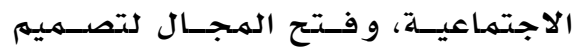

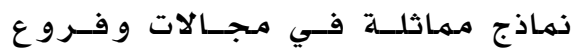

التكنولوجية الرقمية، و بالتالي لا بدّ من

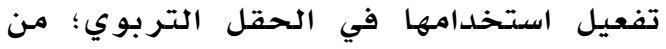
خلال استكشاف الإمكانات التي تمتاز بها هذه التها

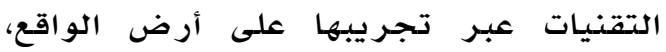

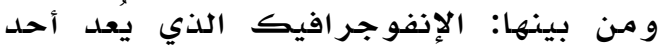

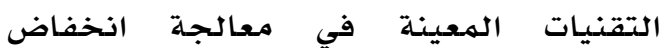

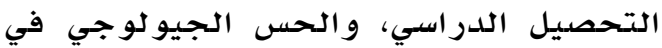

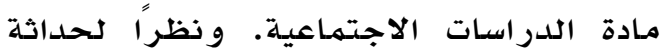

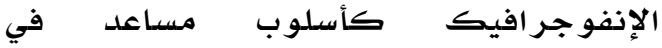

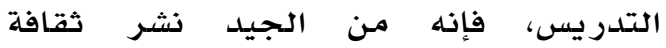

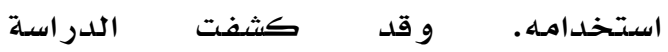

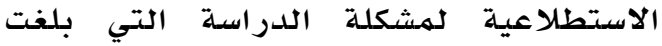

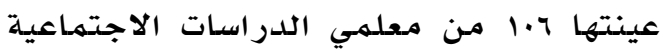

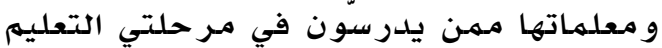

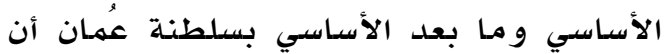

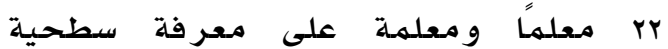
بالإنفوجر افيك، وغالبيتهم يخلطون بينه

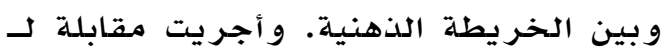

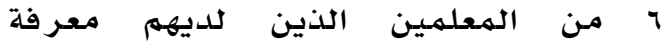
بالإنفوجرافيك، وتبين أنهم غير قادرين على توظيفه، وهذه النتيجة تكشف وجودئ

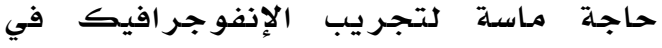

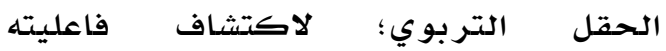
و الصعوبات التي قد تواجه تطبيقه من أجل

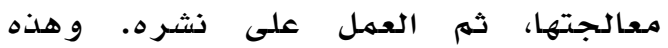
النتيجة تتفق مع توصيات بعض الندوات

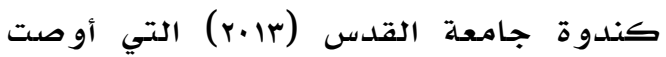

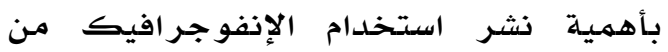
خلال تدريب المعلمين على استخدامـه، وهذا ما دعت إليه فلسفة التربية و التعليم بسلطنة عمان، ووثيقة مناهج الدراسات الاجتماعية للصفوف r - r rإ إذ جاء فيهما ضرورة تنمية مهارات القرن الحسادي والعشرين التي

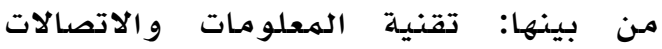

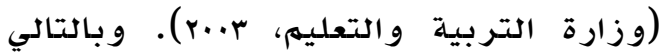
يمكن تلخيص مشكلة الدراسة في السؤال

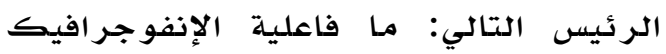

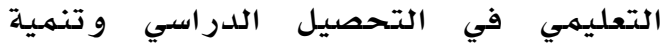

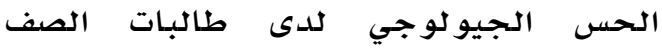
العاشر الأساسي بسلطنة عمان؟ 


$$
\text { التحصيل الدراسي }
$$

يُعرف التحصيل الدراسي بأنسه: "مقــدار مـا

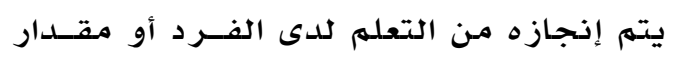

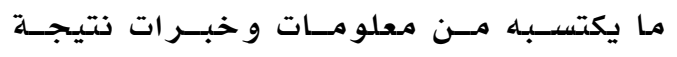

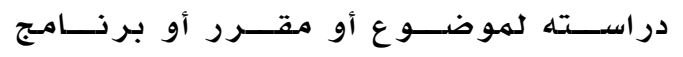

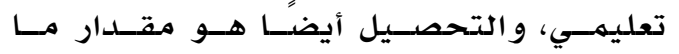
يتحقق فعليا من الأهداف التعليمية، ويقـاس التحاس التهاس

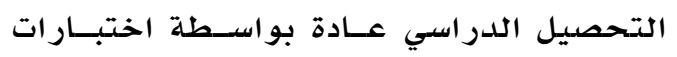

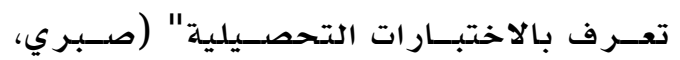

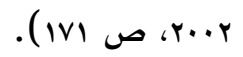

وتعرّفه الدراسة إجرائيًا بأنه: عصيلة

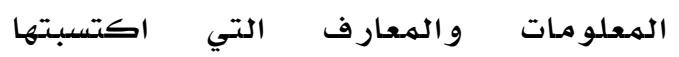

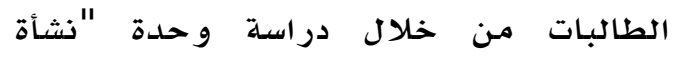

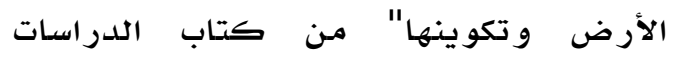
الاجتماعية للصف العاشر الأساسي باستخدام

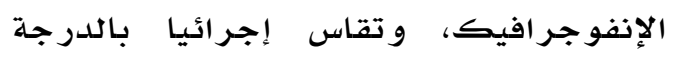

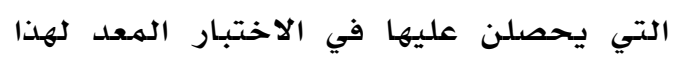

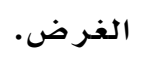

\section{الحس الجيولوجي}

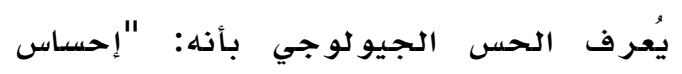

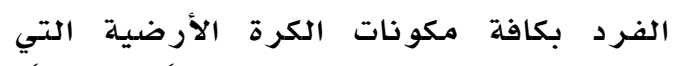

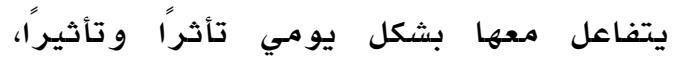

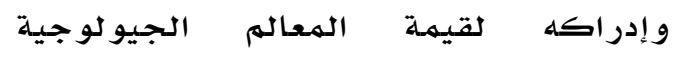
وجماليتها على سطح الأرض التي يتفاعل التهل معها" (Clary \& Wandersee, 2006, p.52) ويُعرف إجرائيًا بأنه: درجة مولة موافقة الطالبات

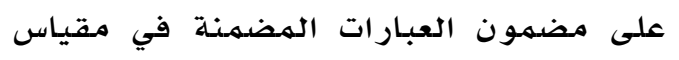

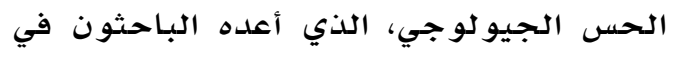

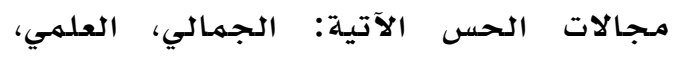

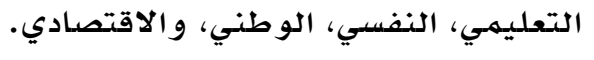

\section{منهج الدراسة وإجراءاتها}

يتضمن هذا الجزء الجوانب التالية: منهج الدراسة

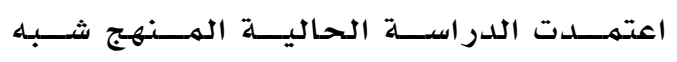

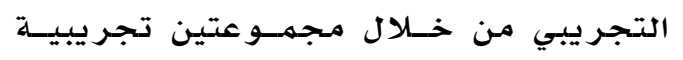

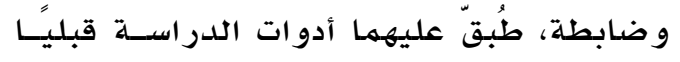
(اختبار التحصيل الدراسي، ومقيـاس الحسبس أدوات الدراسل
علمية أخرى.

تقديم نمـاذج عمليسة لتعزيـز الحسس الحس

الجيو لوجي لدى طالبات الصف العاشر

من خلال الإنفوجر افيك.

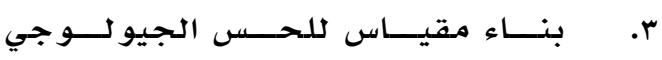

يتضمن مجموعة من الأبعاد الوجدانية لونية

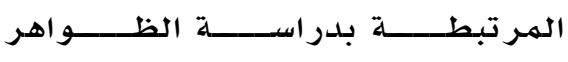

الجيولوجية المختلفة..

؛. نشر ثقافة اسـتخدام الإنفوجرافيـك

في الحقل التربوي.

حدود الدر اسة

اقتصــرت الدراســة علــى معر فــة فاعليــة

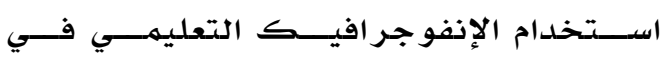
التحصيل الدراسي وتنمية الحس الجيو لوجي الإنواليري

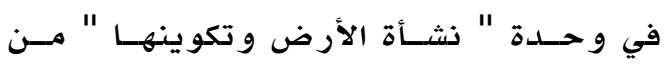

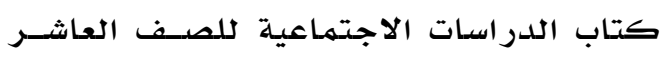

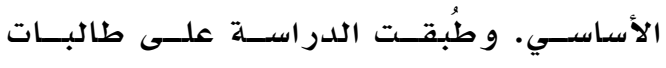

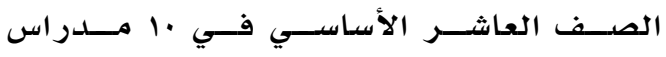

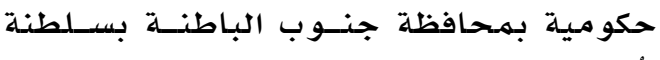

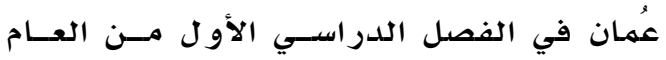

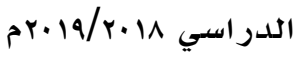
مصطلحات الدراسة الإنفوجر افيك عرّف الإنفوجر افيك بأنه: "تصميم يجمَع

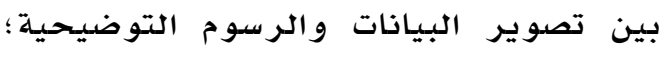

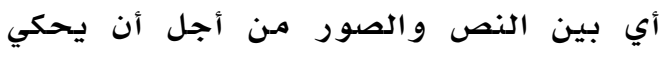

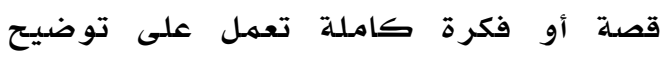

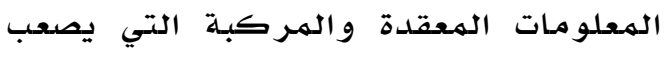

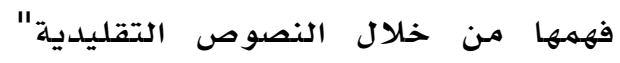
(Krum, 2013, p. 107)

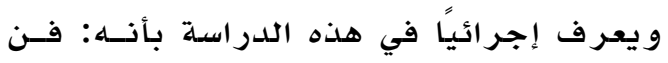

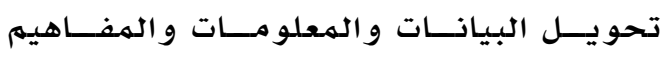

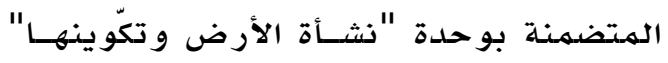

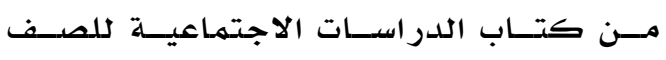
العاشر إلى مجمهوعة مـن الصــور والأثـكال

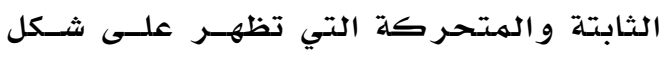
فيديوهات تفاعلية أعدها الباحثون. 
اشتملت خمس مدارس تضمنت بrr طالبـة.

$$
\begin{aligned}
& \text { مواد الدراسة و أدواتها } \\
& \text { أو ثا: مواد الدر اسـة } \\
& \text { تصاميهم الإنفوجر افيك: }
\end{aligned}
$$

أعدّ الباحثون المادة العلمية و السيناريوهات

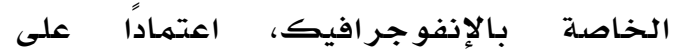

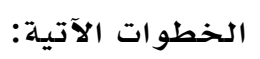

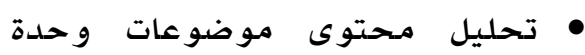

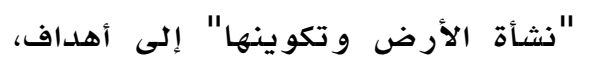

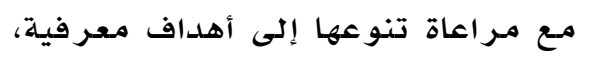
و مهارية، وسلوكية، و تعدد مستو ياتها إلى معرفة وفهم و قدر، ورات عليا. عمل سيناريو لكل هدف من أهداف

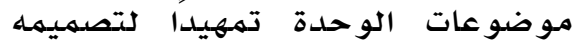
و فقًا لأنهاط الإنفو جرات افيك. • إرسال السيناريو إلى الهصمهم لتحويله إلى نمط إنفو جر افيك. • تصميم الإنفوجر افيك مع الالتزام

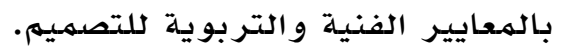

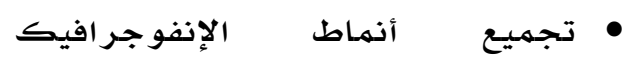

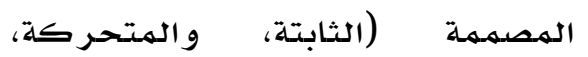

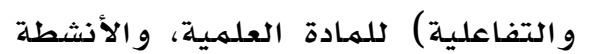
الهصاحبة لها في بر مجية و احدة. إخراج البرمجية في شكلها النهائي،

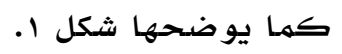

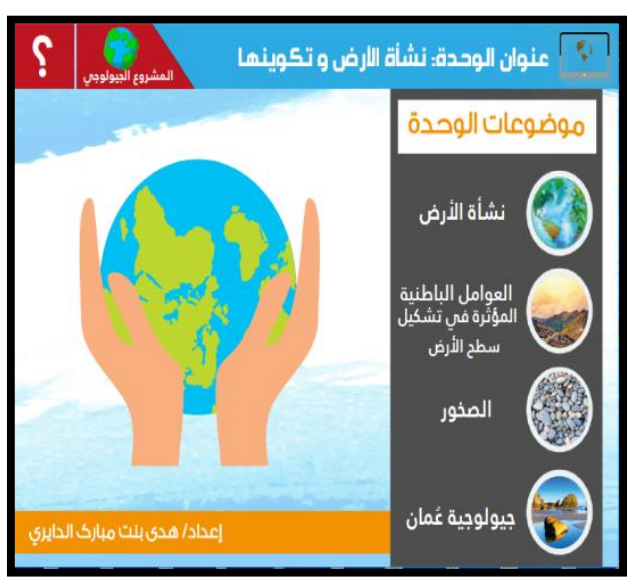

شكل 1: واجهة وحدة"تشأة الأرض وتكوينها" وفقاً لأنماط الإنفوجرافيك

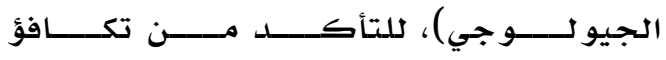

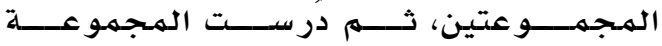

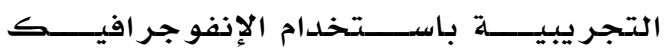

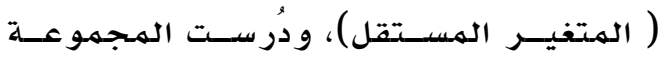
الضابطة باستخدام الطريقـة المعتــادة التـي

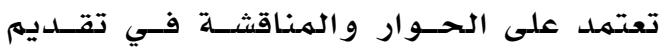
الدرس. و بعد انتهاء الفترة الزمنية ولهية للدراسلة أُعيد تطبيق أدوات الدراسـة (اختبار التحصيل

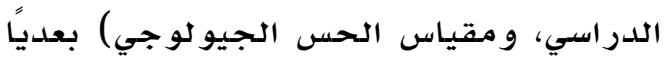

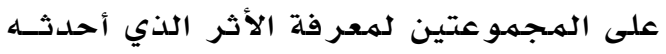
المتغير المستقل على المتغير ات التابعة. مجتمع الدراسة ومينتها

تكّون مجتمع الدراسـة من طالبات الصف

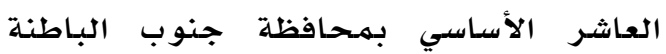

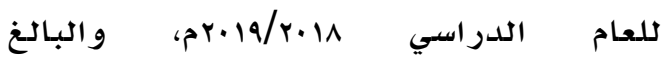
عددهنعVq طالبة مـن خلال بيانات (وزارة

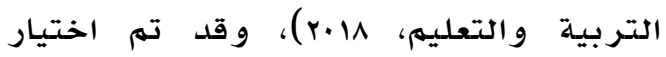
مجتهمع الدراسـة وعينتها من محافظة جنوبه

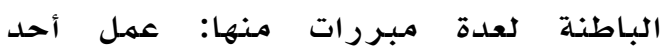

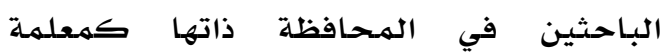

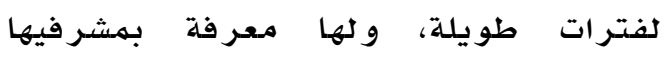

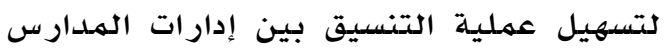

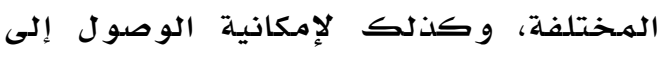

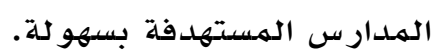
أمـا عينـة الدراسـة فانقسمت إلى ثلاث عينات؛

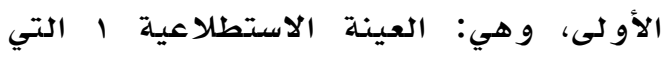

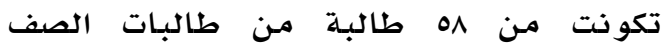

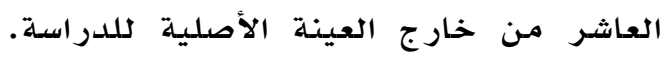
وقد استخدمت هذه العينة في تقدير ثبات الاختبار التحصيلي. والثانية هي العيد العينة

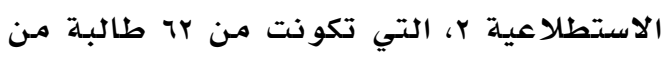

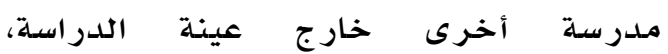
واستخدمت في تقدير ثبات مقياس الحس احس الجيولوجي. أما الثالثة، فهي العينة الأصلية

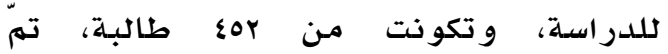

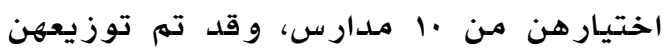

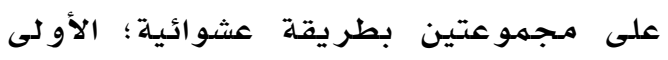

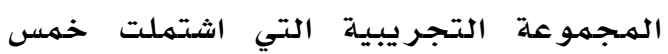

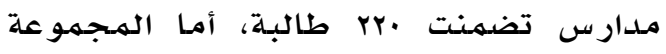

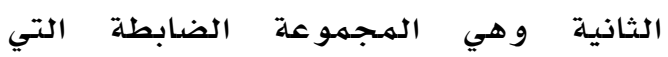


الوحدة، مثل تغيير الهلدف "تفسر أسبـاب

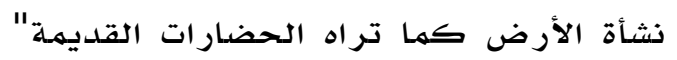

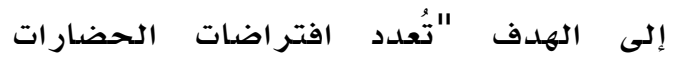
القديمة حول نشأة الأرضد".

ثانيا: أدوات الدراسـة

الاختبار التحصيلي: أُعدّ اختبار تحصيلي

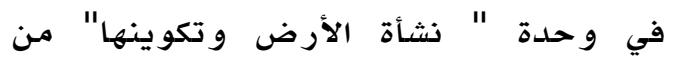
كتاب الدراسـات الاجتمـاعية للصف الداه العاشر الأسـاسي، وبنـي وفقًا للخطوات الاتهاعية الآتية:

تحليل الهـحتــوى لتحديــــ الأهـداف

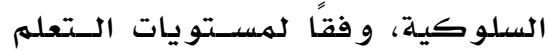

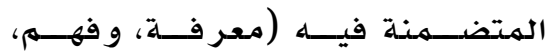

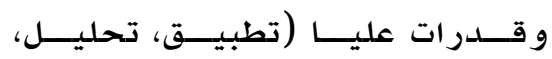
تر كيب، تقويم).

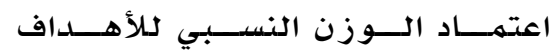
المشار إليها في وثيقة تعلم الطلبسة

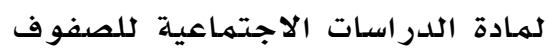
.1.-0

الاطلاع على نمــاذج مــن اختبـارات

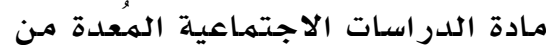
قبل وزارة التربية و التعليه. إعداد جدول مواصفات الاختبـار تبعًا للخطوات التالية:

O تحديد الوزن النسببي للموضــوعات في ضوء عدد الصفحات لكل درس. O تحديد الـوزن النسـبي لمسـتويات الأهداف: معر فة، فهم، قدرات عليا. O تحديد عدد الأسئلة في كـل درس الأس حسب مستو يات الأهداف.

صياغة مفردات الاختبار: تضمن الاختبار

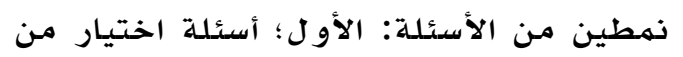

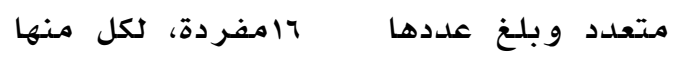

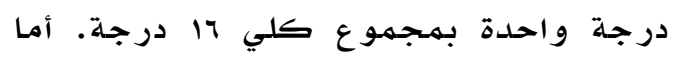

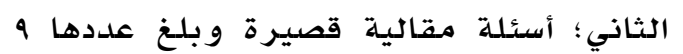

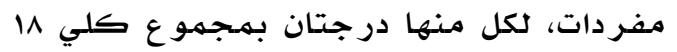

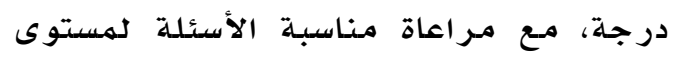

دليل المعلمة

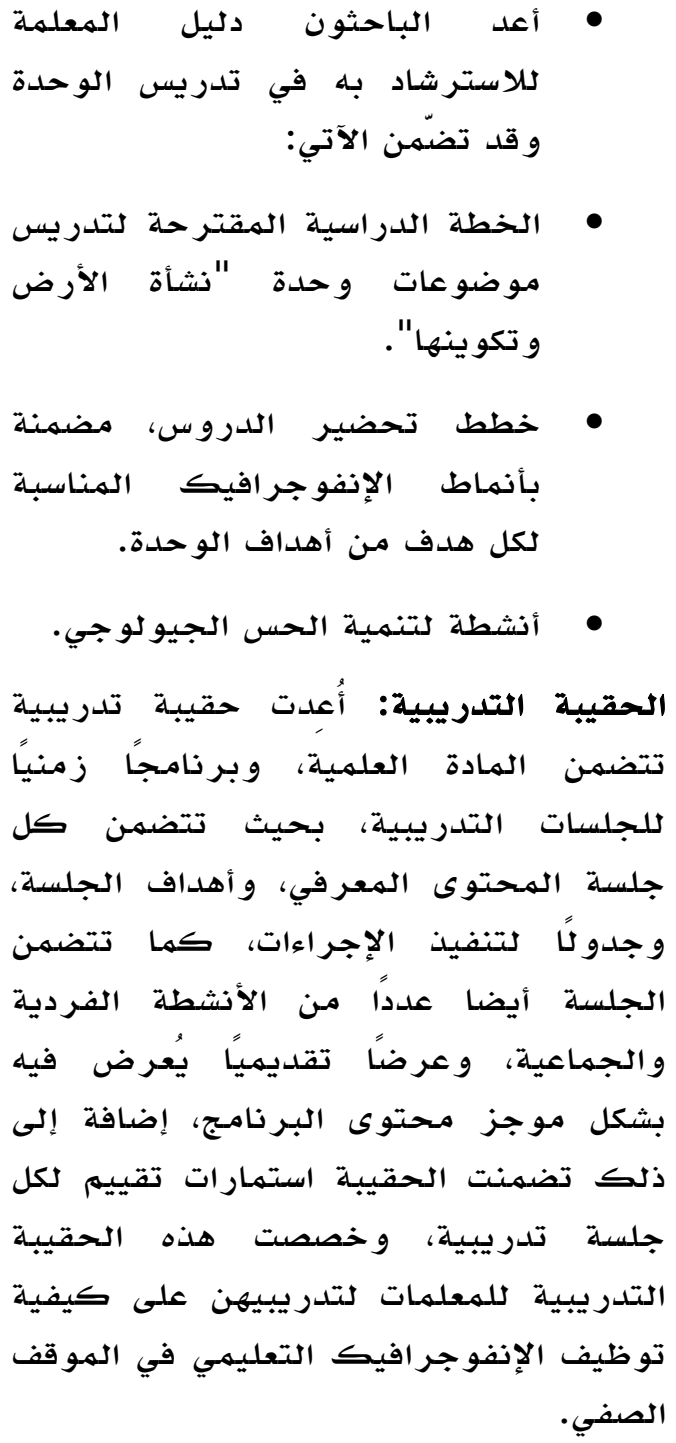


تحديل الهدف من المقياس: يهدف المقياس إلى الكثف عن أثر التدريس و فق البر نامـج

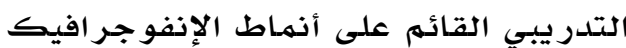

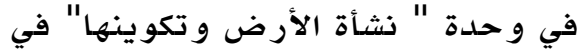

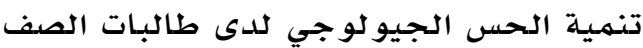
العاشر الأسـاسي. تحديل مححاور المقيـاس: تكونـت الأداة فـي

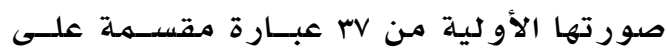

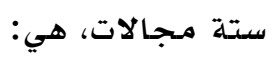

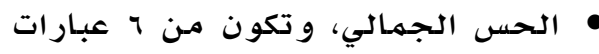
موجبـة، و عبارة و احدة سـالبـة.

• الحس العلمي، وتكون من V عبارات موجبـة، و عبارة و احدة سـالبـة.

• الحس التعليهي، وتكون من ع عبارات موجبـة، و عبارة و احدة سلدالبـة.

• الحس النفسي، وتكون مـ ع عبارات موجبـة، و عبارة و احدة سـالبـة.

• الحس الوطني، و تكون من 7 عبارات

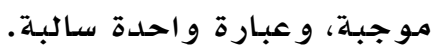

• الحس الاقتصادي، وتكون من ع ع عبار ات موجبة، و عبـارة سـالبة و احدة. صــياغة عبــارات المقيــاس: تنوعست بــين العبار ات الموجبـة، و العبار ات السالبـة، ورووعي

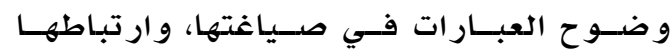

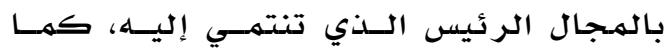

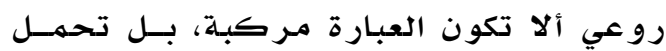

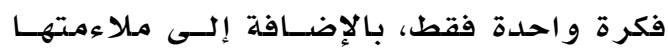
لمستوى طالبات الصف العاشر الأساسي. صدق مقياس الحس الجيولوجي: تمّ التحقق من صدق المقياس بطريقتين: أو لاً: صدق الهدكمين تُحقق من صدق المقياس بعرضهـ على ه من

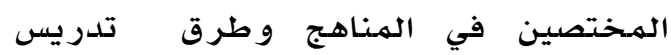

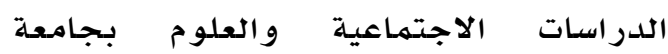

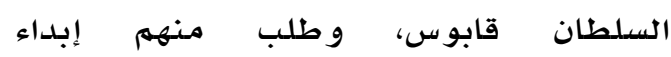
مـلاحظاتهم حول المقياس؛ من حيث مـلاءمة

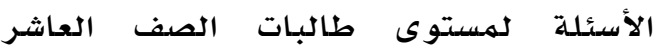

طالبات الصف العـاشر الأساسي. و اُختير هذا

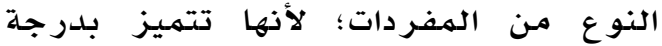
عالية من الموضوضعية، و تغطي مساحة واسعة

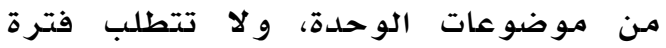
زمنية طويلة لتدوين الإجابة.

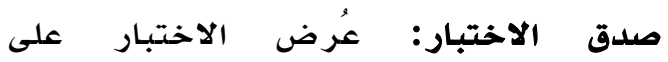
مجموعة مـن المحكمين المـختصين في قسهم

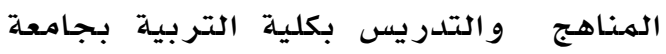

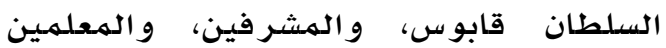

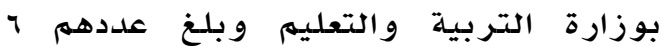

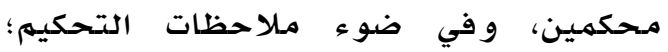
أُجريت بعض التعديلات من حيث ميثرء إعادة

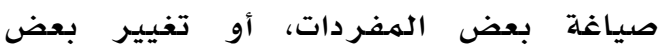

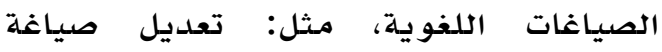

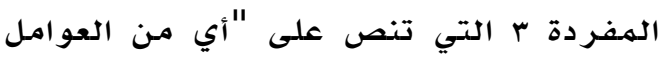

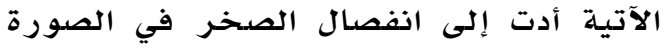

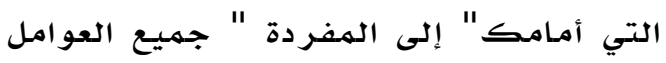

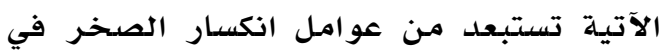

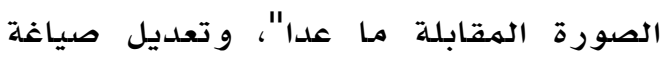

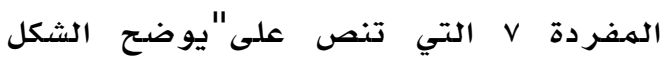

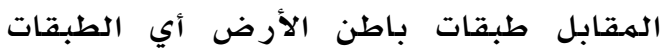
أكثر حرارة" إلى المفردة "الطبقة الأكثر حرارة كما هو و واضح في الشكل الهقابل". تحديد زمن الاختبار: تم تحديد زمن الاختبار من خلال حساب انتهاء أول طالبة في الإجابة

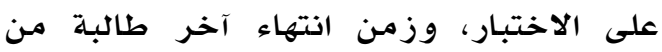

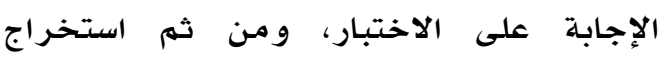
متوسط الزمنين والذي تراوح هـ دقيقة، لذا

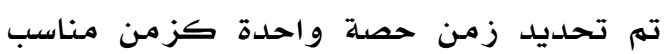
لكلإجابة على الاختبار.

ثبات الاختبار:تم حساب معامل الثبات بطريقة

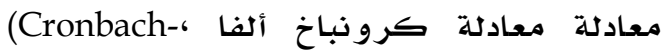
Alpha) هذه القيمة دالة على ثبات الاختبار. مقياس الحس الجيولوجي: بعد الاطلاع على

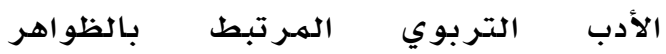

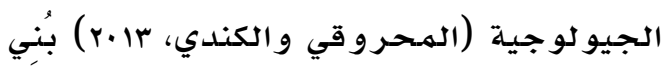

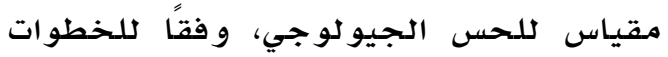
الآتية: 
و الدرجة الكلية للهقياس، وجلدول ا يوضح

$$
\text { ذلك. }
$$

جدول 1

نتائج معاملات الارتباط بين درجات كل مجال على حدة وبين الارجة الكلية للمقياس ككل

\begin{tabular}{|c|c|}
\hline قيمة معامل الارتباط & المجال ل \\
\hline$* * .741$ & الحس الجمالي \\
\hline$\frac{* *}{*} .9 \vee \wedge$ & الحس العلمي \\
\hline$* \% .97 r$ & الحس التعليمي \\
\hline$* * . V \vee T$ & الحس النفسي \\
\hline **..10 & الحس الوطني \\
\hline **.V9Y & الحس الاقتصادي \\
\hline
\end{tabular}

من خلال جدول ا يمكن مـلاحظة أن مجالات

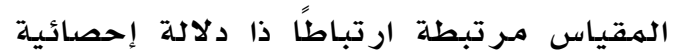

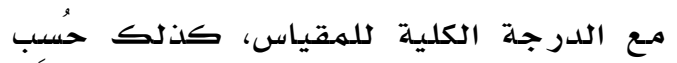
صدق تمايز العبارات بإيجاد معامل الارتباط العاطيه بين كل عبارة مـن عبارات الهقياس و الدرجة الدية

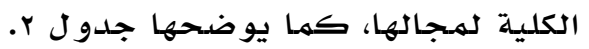

الأساسي، و مدلى مناسبة العبارات لمجالات

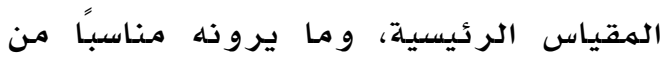

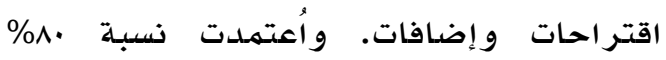
كنسبة اتفاق بين الهـحكمين، وقد أقرّ معظم إتهات المحكمين المقياس، كما هو مـع مقترحات بتعديل صياغات بعض العبارات مثل: العبارة

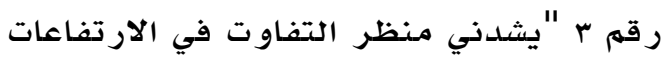
في السلاسل الجبلية"، إلى "يشدني منظئر

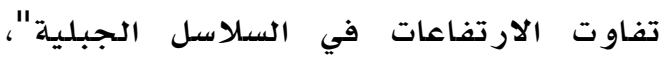

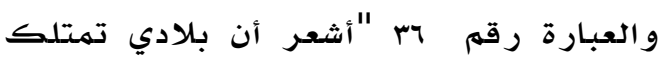

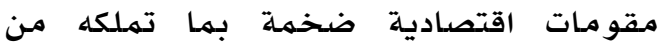

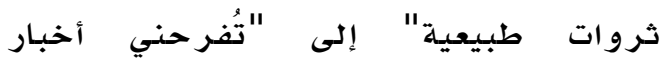

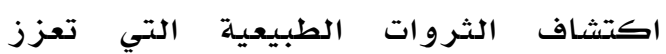
اقتصاد بلادي". ثانيا: صدق تمايز عبار ات الهقياس تم حساب صدق تمايز عبارات مقياس الحس

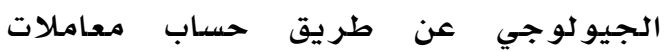

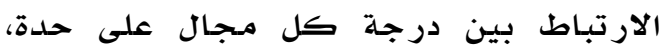

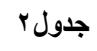

معامل الارتباط بين كل عبارة من عبارات المقياس والدرجة الكلية لمجاله

\begin{tabular}{|c|c|c|c|c|c|}
\hline قيمة معامل الارتباط & رقم العبارة & المجالات الرئيسية & قيمة معامل الارنباط & رقم العبارة & المجالات الرئيسية \\
\hline **.OH人 & rI & الحس النفسي & $* * .7 \mathrm{VV}$ & 1 & الحس الجمالي \\
\hline$* \%$ * $\{0 \leqslant$ & rt & & $\% * 707$ & r & \\
\hline$* * .0 V r$ & rt & & $* * 0.1$ & $r$ & \\
\hline **.orq & $r \varepsilon$ & & $* * . \leqslant 0 \leqslant$ & $\varepsilon$ & \\
\hline$* \% .794$ & ro & & ***. & 。 & \\
\hline *.rT & r & الحس الوطني & $* * . V \leq 4$ & 7 & \\
\hline$* * .09$. & rr & & ***Vrᄉ & v & \\
\hline ***.Tr人 & rA & & ***...1 & $\wedge$ & الحس العلمي \\
\hline$* * . V \mu V$ & rq & & 满華.TY & 9 & \\
\hline$* * 79 \mathrm{~V}$ & $r$. & & $* * . \leqslant$ \% & 1. & \\
\hline$* * .0 \leq \varepsilon$ & r & & 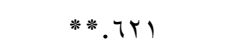 & 11 & \\
\hline **.TAr & Tr & & $* * \vee \vee r q$ & ir & \\
\hline$* * .71 r$ & r & الحس الاقتصادي & $\cdots+1$ & ir & \\
\hline$* * .0 \leqslant r$ & $r \varepsilon$ & & **.orq & $1 \varepsilon$ & \\
\hline$* * .0 V \varepsilon$ & ro & & $* * .0 \leqslant \wedge$ & 10 & \\
\hline$* * .090$ & דו & & $* *$. V O Y & 17 & الحس التعليمي \\
\hline \multirow[t]{5}{*}{$* * .001$} & rv & & $* * . V \varepsilon \varepsilon$ & iv & \\
\hline & & & $* * .717$ & 11 & \\
\hline & & & $* * . \vee 99$ & 19 & \\
\hline & & & $* * . \vee \leq r$ & $r$. & \\
\hline & & "دالة عند مستوى & \multicolumn{3}{|c|}{ ** دالة عند مستوى | .,., . } \\
\hline
\end{tabular}




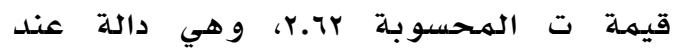

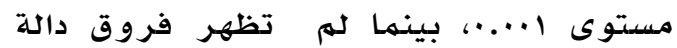

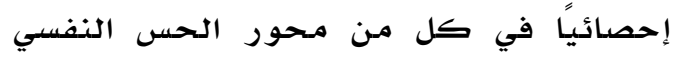

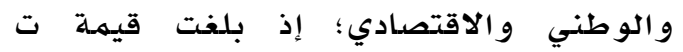

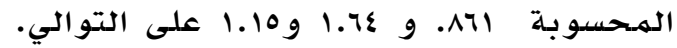
و يستدل من ذلك على عدم تكافؤ مجموعتي الدراسلة في مقياس الحس الجيولدوجي. إجر اءات الدراسة تمثلت إجراءات الدر اسـة في الخطوات الآتيلة:

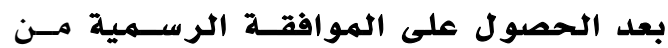

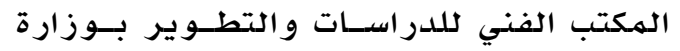

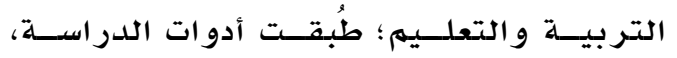

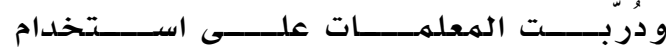
الإنفو جر افيك.

التطبيق القبلي لأدوات الدراسة: طُّق اختبار

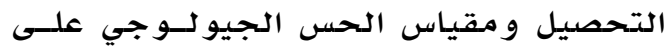
مجهمو عتي الدر اسلة.

البدء بالتطبيق الفعلي للدراسـة: اسـتغرقت

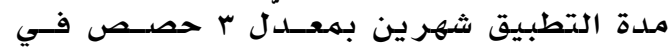

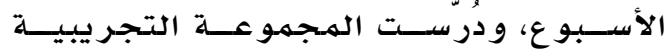
باستخدام الإنفوجر افيك التعليهي، في حسين استمر تدريس الهـمهوعة الضابطة بالطريقة المعتادة.

التطبيق البعلدي لأدوات الدراسة بعد انتهـاء

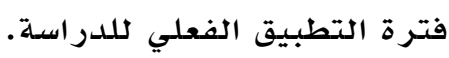

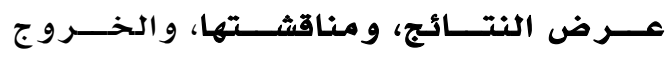

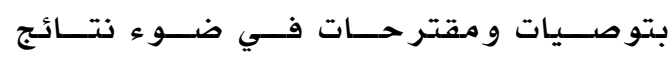

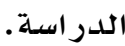

\section{المعالجة الإحصائية}

ا. المتوس ســطات الحســـابية و الانحر افــات

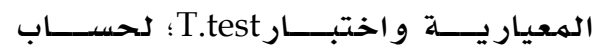

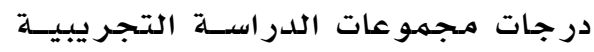
و الضـابطة للطالبــات، علـى الاختبــار

التحصيلي، و مقياس الحس الجيولوجي.

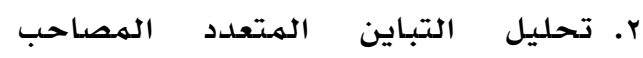
(MANOVA) مقياس الحس الجيولوجي لتحديد
ويتضح من جدول r ثبات مقيـاس الحس الجيو لوجي: حسبست معامـلات الاتسـاق الداخلي للهقياس بطريقة كرونباخ ألفا، حيث بلغت قيمة معامل الثبات 179. · في المقياس ككل،

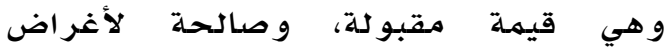
الدر اسـة الححالية.

زمن مقياس الحس الجيولوجي: لحساب الزمن الكلازم لتطبيق المقياس تم تحديل

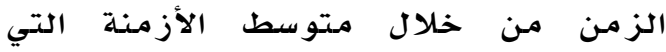

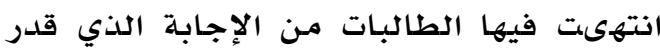
بـ بـ بـ دقيقة.

التحقق من تكافؤ مجموعتي الدراسة في القياس القبلي: التحصيل الدراسي

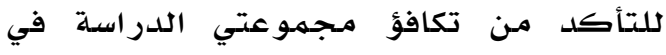

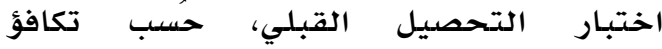

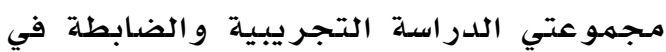
اختبار التحصيل الدراسي القبلي، وحسببت

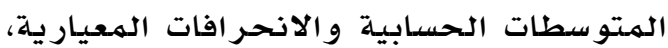
وقيمة ت لأداء الطالبات، وتبين أنه لا توجد فروق دالة إحصائيا بين الهجموعتين، حيث

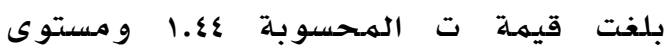
دلالتها 101..، وهو مستوى دلادة أكبر من

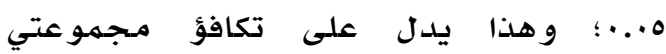

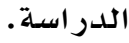

\section{مقياس الحس الجيولوجي}

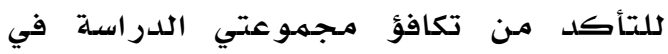

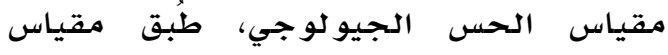

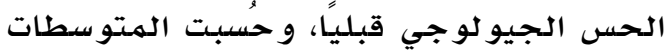

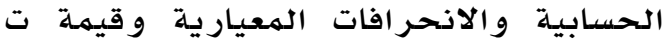
لنتائج الطالبات، وتبين أنه توجد فروق دالدئ دالة إحصائيًا بين المهجموعتين؛ حيث بلغت قيمهة

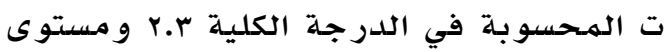
دلالتها IV V... وهي دالة عند مستوى دلالة

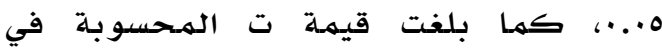
محور الحس الجمالي 9..ب، ومحور الحس النفسي آیی. ، وهي دالة عند مستوى دلالة ๑.. 
و تقريب الواقع إلى أذهان الطالبات مـن خلال

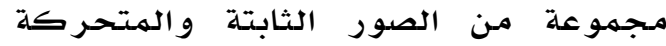

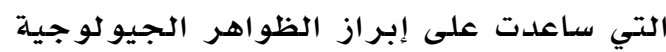

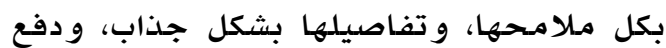

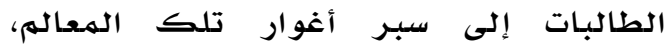

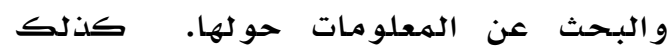

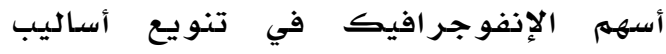

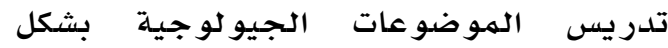

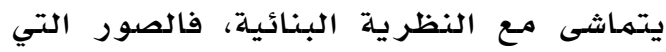

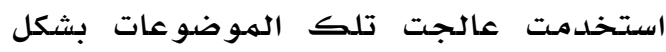

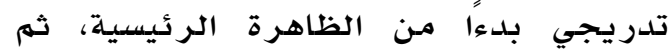

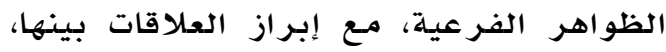

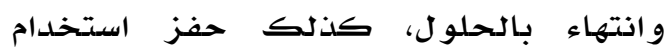
الإنفوجر افيك المعلمات إلى تنويع الأنشطة

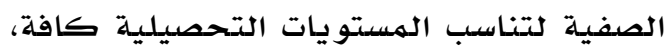

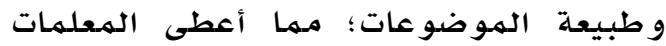
مساحلة أوسـع من للتوسيع في المـادة العلميـة. كما تعزى هذه النتيجة إلى الأثر الذي

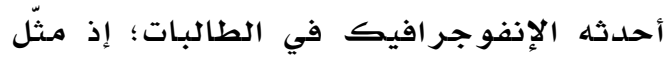

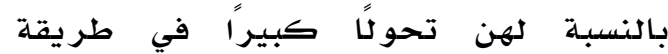
التدريس، وهذا التغيير في نمط التدريس نهون

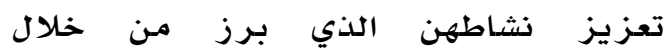
مشاركتهن الواسعة في كافة الأنشطة الصفية، وحرصهن الشديد على فهم أبعاد

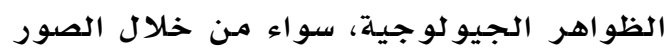

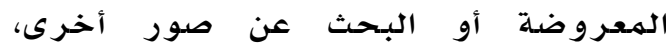

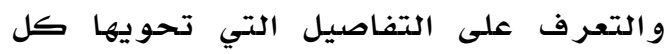
صورة، وأماكن انتشار الظاهرة التي تعبر

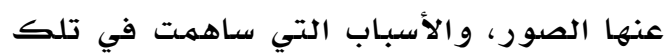

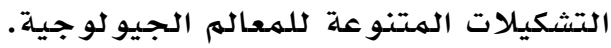

كما ت تعزى هذه النتيجة إلى دور

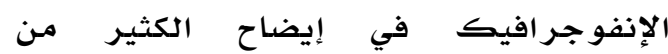
الظواهر الجيولوجية التي تحتويها و وحدة

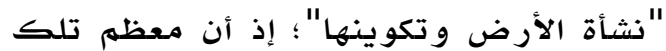
الظواهر عرضت على هيئة نصوص، وأحيانًا

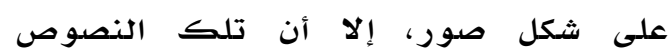

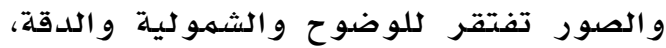

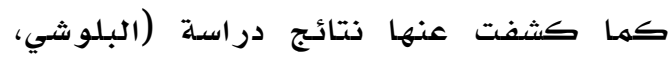

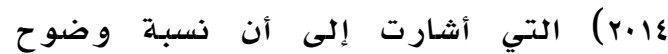

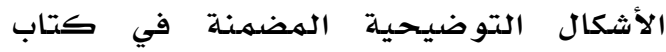

مصدر الفروق والتباينات البعدية

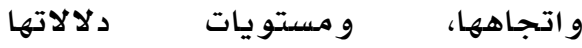

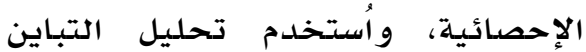

المتعدد الهصاحب لتحديد الفروق بين

مجهموعتي الدراسلة التي بينتها نتائج

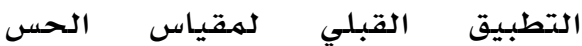

الجيو لو جي.

\section{نتائج الدراسة}

للإجابة عن السؤال الأول النذي نص على:

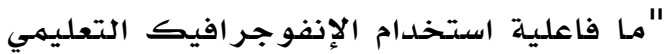
في التحصيل لدى طالبات الصف العاشر

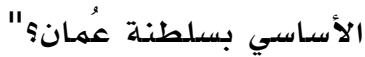

و للتحقق من الفرضية المنبثقة منهـ طُبق

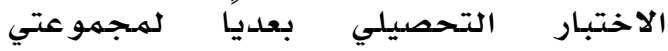

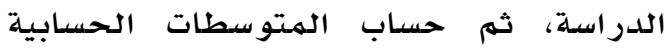

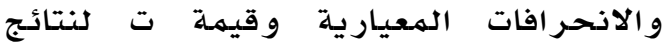
الطالبات في الاختبار كما يوضدحه جدو ل r.

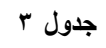

المتوسطات الحسابية والانحرافات المعيارية وقيمة (ت) لأداء الطالبات في اختبار التحصيل البعدي

\begin{tabular}{|c|c|c|c|c|c|}
\hline قيمة & قيمة & الانحراف & المتوسط & العينة & مجموعتا \\
\hline الاحتمال & ت & المعياري & الحسابي & & الدراسة \\
\hline \multirow[t]{2}{*}{${ }^{*} \ldots$} & ᄉ.) & 0.19. & YI.IV & Y.r & التجريبية \\
\hline & 1 & $0.7 \vee \wedge$ & 17.7. & YYE & الضابطة \\
\hline
\end{tabular}

يتبين من جدول r م على وجود فرق دال إحصائيًا تعزى إلى متتغير طريقة التدريس وجس

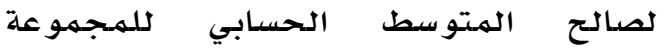

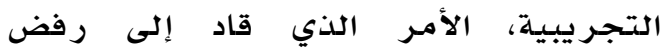
الفرضية الصفرية وقبول الفرضية البديلة، و هي: يوجد فرق دال إحصائيا عند مستوى

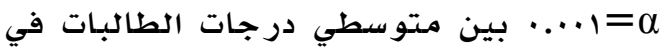
الاختبار التحصيلي في التطبيق البعدي تعزى لطريقة التدريس.

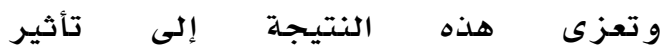

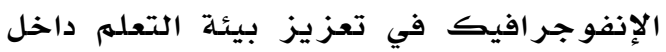

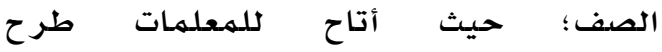
الهوضوعات بشكل مبسط و متسلسل، 
Holmquist et al., 2009; الطلبة من فهمها

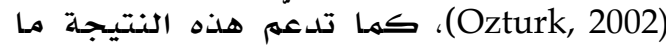

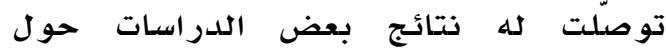
فاعلية الإنفوجر افيك في تعزيز التحصيل

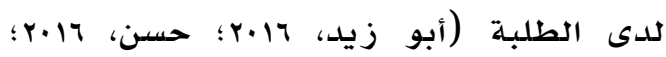

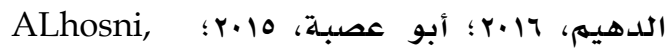
Çifç, ; Ebaid, 2016 ALshehri \& 2016 . $(2016$

للإجابة عن السؤال الثاني، و نصيّه "ما فاعلية

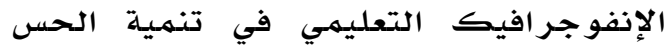

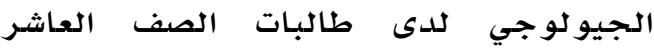
الأساسي؟"، و للتحقق من الفيوي الفرضية الهنبثقة

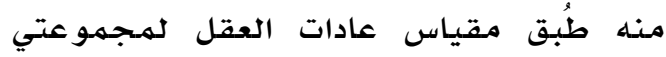

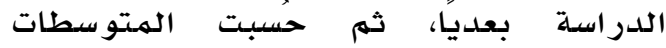

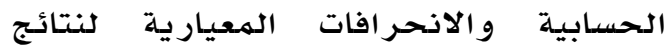
الطالبات في كل مظهر من مظاهر الحس والحسر

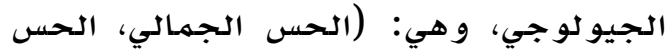

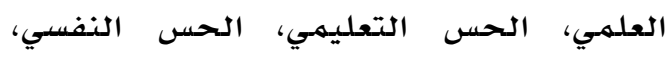

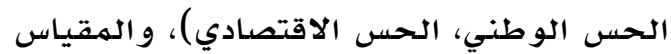
ككل كما يوضحسه جدو ل ع. يتبين من جدول ع وجود فروق ظاهرية بين متوسطات درجات طالبات مجهموعتي الدرو اسلة

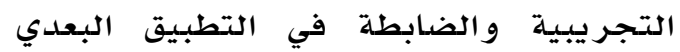

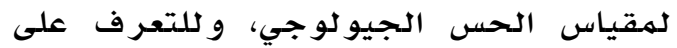

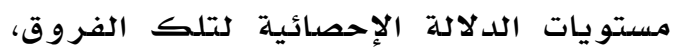

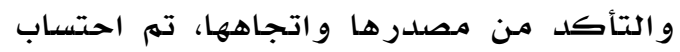
قيم ويلكس لمبدأ (Wilks Lambda)، و كانت

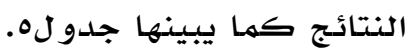

يتضسح من جدول ه أن قيهم ف المحسوبة على قيهم ويلكس لمبدأ تشير إلى وجود فرق هر دال

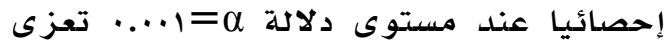

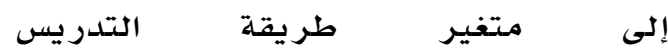

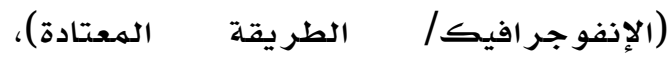
و لتحديد اتجاه الفرق، ومستويات دلالاتها الإحصائية في كل فحل محور من من محاور

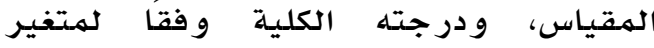
المهموعة، استخلدمت نتائج تحليل الهيل التباين المتعدد المصاحب (MANCOVA) كما هو، هو الهول

$$
\text { مبين في جلدو ل الهدادد }
$$

الدراسات الاجتماعية للصف العاشر بسلطنة

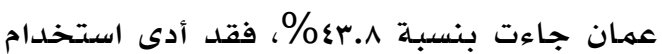
الإنفوجر افيك إلى عرض صور جلديدة لذاء

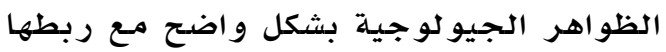
بعدد من الروابط الإبكترونية التي تتيح

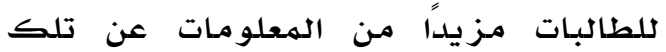
الظواهر، و مواقعها على خارطة العالهم. بالإضافة إلى ذلك، مكّن الإنفوجر افيك

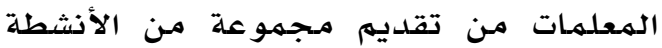

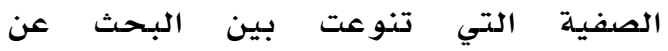

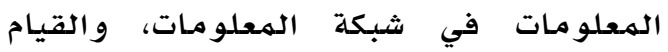

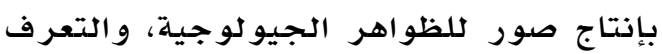
على مواقع المعالم الجيول لوجية، و وكتابة

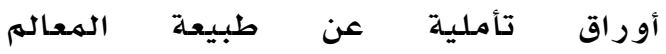
الجيولوجية، بالإضدافة إلى التقويهم البنائي

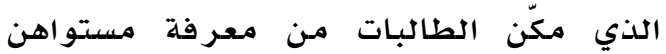

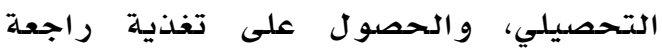
فورية

وقد تعزى هذه النتيجة إلى الأنشطة

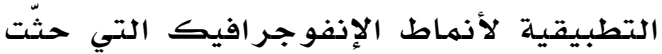
الطالبات إلى مزيلـ من البـحث عن الهعلو مـات

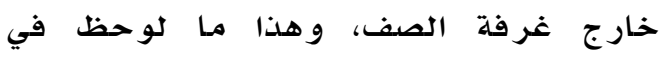
الموقف الصفي؛ من خلال طرح الطالبات

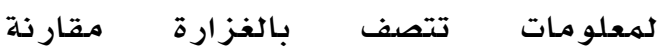

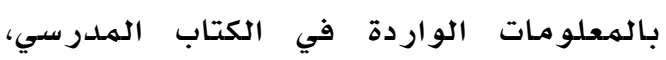

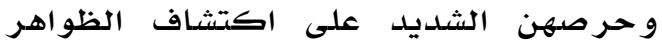

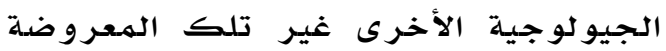
في الكتاب المدررسي. وهذه النتيجة تلدعم ما ذكرته الأدبيات عن القدرة الفائقة لإنفوجر افيك في تصديم الصور والرسومات والشروحات بطريقة

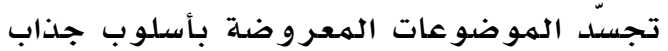

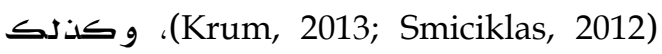
تسمـح بعرض سلسلة مـن الصدور بشكل سريـع

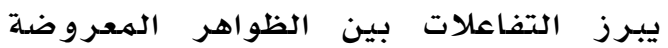

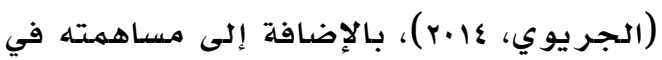

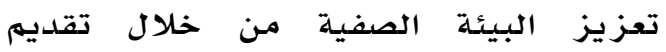
الموضوعات بصورة شائقة، و عر ض المفاهيم

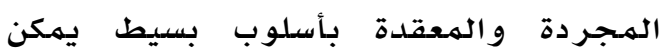




\section{جدول ؛}

المتوسطات الحسابية والانحرافات المعيارية لأداء طالبات مجموعتي الدراسة في محاور الحس الجيولوجي البعدي وفقًا لمتغير المجموعة

\begin{tabular}{|c|c|c|c|c|}
\hline الانحراف المعياري & المتوسط الحسابي & 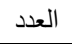 & المجموعة & محاور الحس الجيولوجي \\
\hline .971 & $\leq . .7$ & rir & التجريبية & 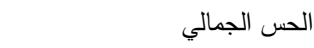 \\
\hline $1 . .79$ & $\varepsilon . .1$ & rrA & الضابطة & \\
\hline .970 & r.т. & rir & التجريبية & الحس العلمي \\
\hline $1.0 \leqslant$ & $r .91$ & rru & الضابطة & \\
\hline $.9 \vee \wedge$ & r.ov & rir & التجريبية & الحس التعليمي \\
\hline $1 . .1$. & r.r. & rYA & الضابطة & \\
\hline $.99 \leq$ & T.TV & rit & التجريبية & الحس النفسي \\
\hline $1 . .71$ & r.VY & rru & الضابطة & \\
\hline $1 . .1 r$ & r.9r & rit & التجريبية & الحس الوطني \\
\hline $1.11 \mathrm{r}$ & $r . \wedge \varepsilon$ & rrA & الضابطة & \\
\hline $1 . . r T$ & r.97 & rir & التجريبية & الحس الاقتصادي \\
\hline 1.15. & r.vq & rrA & الضابطة & \\
\hline . Nor & r.^. & rir & التجريبية & الدرجة الكلية \\
\hline .900 & $r .7)$ & rrA & الضابطة & \\
\hline
\end{tabular}

نتائج تحليل التباين المتعدد المصاحب طبقا لقيم (ف) المحسوية على قيم ويلكس لمبدأ استجابات الطالبات على مقياس الحس الجيولوجي في التطبيق البعدي مصدر النباين

*...

جدول

نتائج تحليل التباين المتعدد المصاحب (MANCOVA) لاستجابات الطالبات على محاور مقياس الحس الجيولوجي في التطبيق البعدي

\begin{tabular}{|c|c|c|c|c|c|c|}
\hline حجم الأثز & مستوى الدلالة & قيمة ف & متوسط المربعات & مجموع المربعات & محاور المقياس & مصدر التباين \\
\hline$\ldots 1$ & $.0 . r$ & . sor & $. \leqslant V)$ & 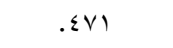 & الجمالي & طريقة التدريس \\
\hline .94 & $* \ldots$ & $\varepsilon \varepsilon .0 V \varepsilon$ & $\leq 0.19 \mathrm{~V}$ & $\leq 0.19 \mathrm{~V}$ & العلمي & \\
\hline. $.1 \mathrm{~V}$ & $* \ldots 7$ & $V .0 \leq \leqslant$ & 1..ov & A..oV & التعليمي & \\
\hline$\ldots$ &.$V Y$. & $.1 Y 9$ & $.1 \mathrm{H}$ & $.1 \mathrm{HA}$ & النفسي & \\
\hline$\ldots r$ &.$\varepsilon \cdot \varepsilon$ & .791 &.$\vee 9 \varepsilon$ &.$\vee 9 \varepsilon$ & الوطني & \\
\hline$\ldots v$ &..$v V$ & r.וr & $r .7 \leq 9$ & $r .7 \leq 9$ & الاقتصادي & \\
\hline \multirow[t]{15}{*}{. $.1 r$} & *..r. & $0 . \leqslant \pi$ & 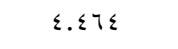 & $\varepsilon . \leqslant 7 \leqslant$ & المجموع الكلي & \\
\hline & .10 & r..Ar & r.IV. & r.IV. & الجمالي & المتغير المصاحب \\
\hline &. .17 & $0.1 \cdot 1$ & 0.19. & 0.19. & العلمي & (النطبيق القبلي) \\
\hline & .719 & $. r \leq \wedge$ & Dצ & פצ & التعليمي & \\
\hline & rot & . nor & .911 & .911 & النفسي & \\
\hline & $.94 V$ & $\ldots \wedge$ &. .1 &. .1 & الوطني & \\
\hline &.$r T$. & $1 . \leq \leqslant \leq$ & 1.7kr & 1.ror & الاقتصادي & \\
\hline & $. r I \leq$ & $1.0 \leqslant 7$ & $1 . r V 1$ & $1 . r v 1$ & المجموع الكلي & \\
\hline & & & $1 . . \leqslant r$ & $\{00 . r v 1$ & الجمالي & الخطأ \\
\hline & & & $1 . .1 \leq$ & $\varepsilon \varepsilon r .1 \cdot 1$ & العلمي & \\
\hline & & & $1 . .71$ & $\leq 77.79$. & التعليمي & \\
\hline & & & $1 . .79$ & STV.IT. & النفسي & \\
\hline & & & $1.1 r \mathrm{~s}$ & $\leq q \vee .1 . \leq$ & الوطني & \\
\hline & & & 1.170 & $0.9 . Y \wedge \varepsilon$ & الاقتصادي & \\
\hline & & & .Arr & roq.r 5. & المجموع الكلي & \\
\hline
\end{tabular}




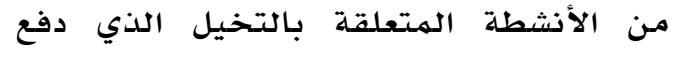

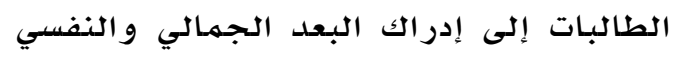
لهذه المعاله، و إمكانية توظيفها سياحيًا. وقد تعزى إلى طبيعة موضوعات الوحدة

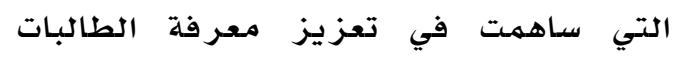
بالمعالم الجيو لوجية في السلطنـة و ما تمتاز به من تنوع سواء كانت مناطق جبلية

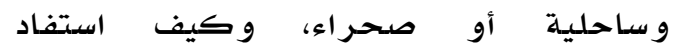

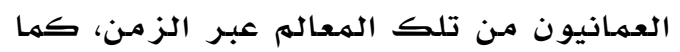

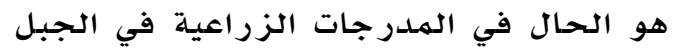

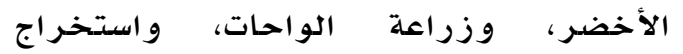

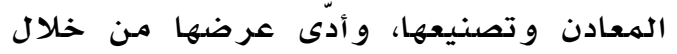
الإنفوجر افيك إلى إدرات الطالبات لأهمية وادية

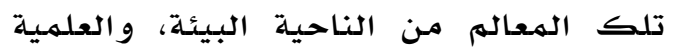

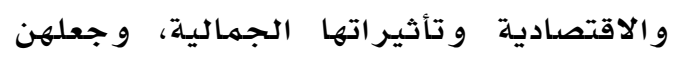
يشعرن أن تلك الهعالم أكثر من كونها تشكيلات صخريـة أو رمال شاسعة. كذلك ساعد قيام الطالبات بتصميه

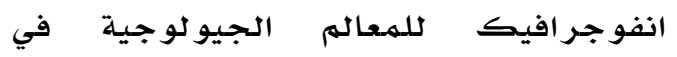

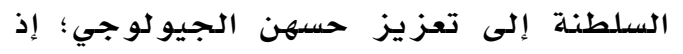

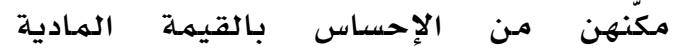

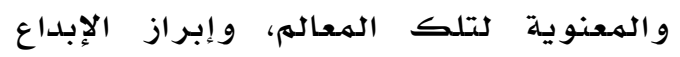

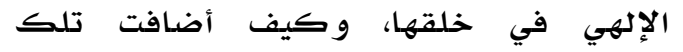
المعالم للهكان بعده الإستر اتيجي والهي والسياسي واتهي

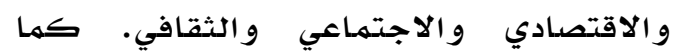
حفّز الطالبـات إلى إبراز الحياة الاجتمهاعية

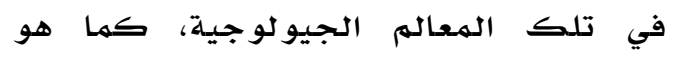
الحال في القرى الجبلية والأودية والسواحلية الهل

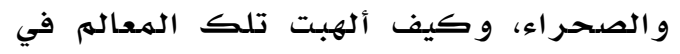

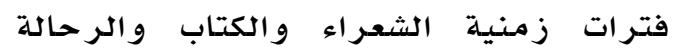
الذين وصفوا جمالها، و تكيف الإنسان معها. وقد شكلت الصدور الثابتة والمتحركة

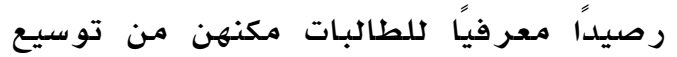

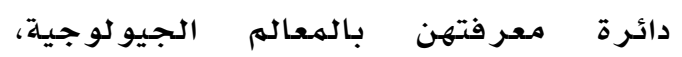
وشجعهن على اكتشاف أسرار تلك المعاله؛

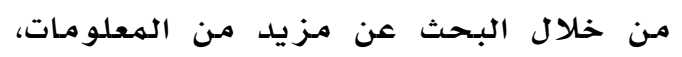

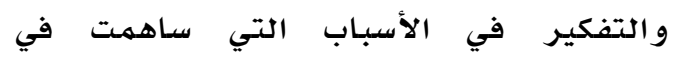

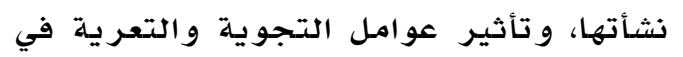
تشكيلها، و ساعدت على اكتسابهن المعلو ماتيرات
يتبين من جدول 1 أن قيم ف دالة إحصائيا

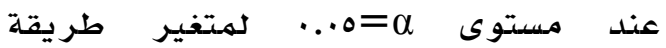
التدريس في الدرجة الكلية، و الهحور العلمي

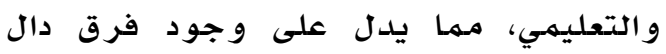
إحصائيًا تعزى إلى متغير طريقة التدريس

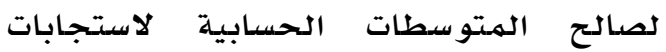

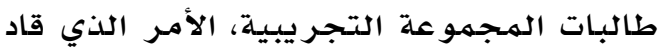

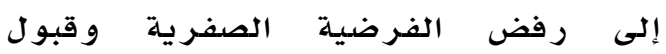

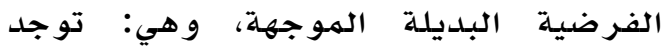

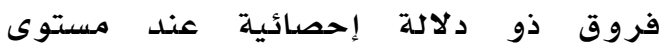

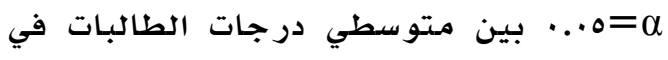
مقياس الحس الجيولوجي في التطبيق لونيق

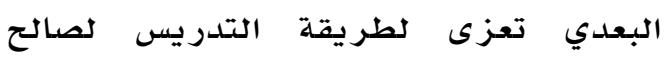
المجمبو عة التجري يبية.

و يمكن أن تعزى هذه النتيجة إلى طبيعة

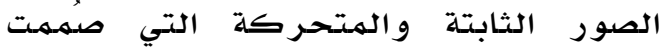
باستخدام لمعالجية

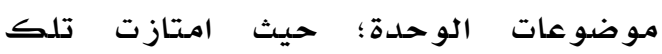
الصور بقدرتها على إبراز الجوانب الجمالية

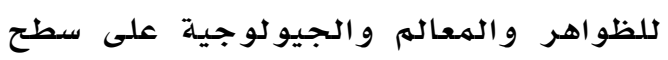

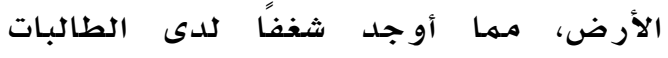
بالتعرف عليها أكثر، والتساؤل حول الألوان

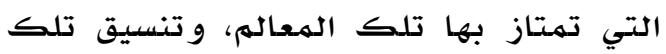

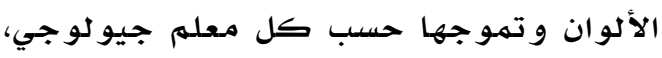

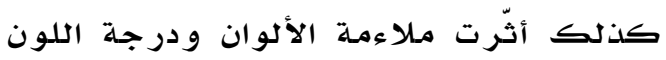
على مشاعر الطالبات و أحاسيسهن، و هذا برز بشكل واضسح من خلال إعجابهن الشديد

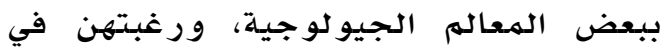
زيارة تلك المعاله.

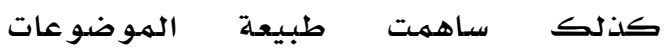

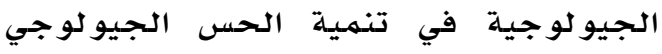

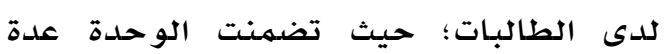
معالم جيولوجية في سلطنة عمان وخارجها، وبعض تلك المعالم قد شـاهدتها الطالبـات

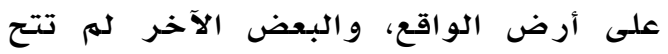
لهن الفرصة لذلك، وهذا جذب اهتمامهن

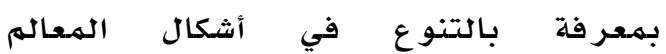

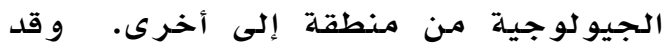

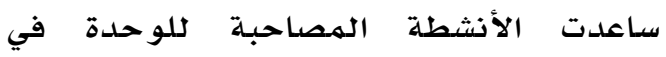
تعزيز الحس الجيولوجي؛ إذ تضمنت العديد 


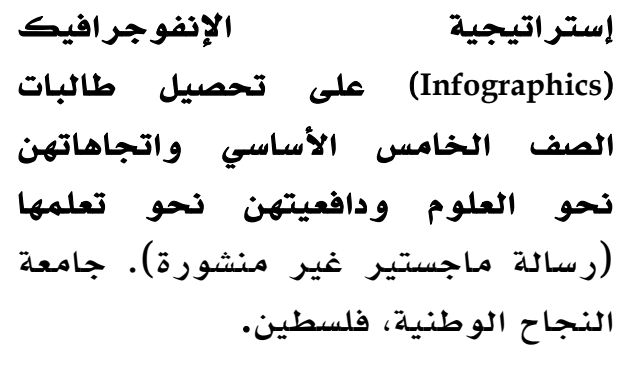

بأحمد، جويدة (17.r). علاقة مستوى الطموح

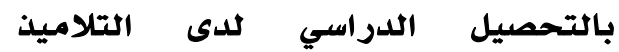
المتمدرسين بمركز التحميل التعليم والتكوين

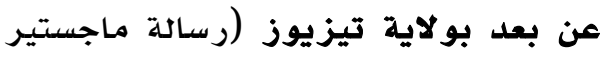

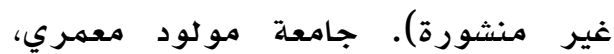

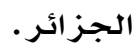

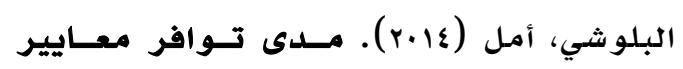

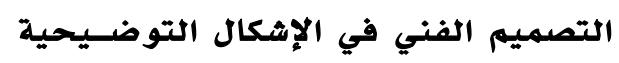
المتضمنة في كتب الدراسات الاجتماعية

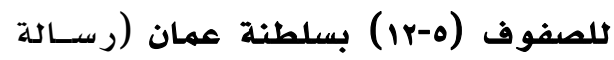
ماجستير غير منشورة). جامعة السلطان قابوس، سلطنة عمان.

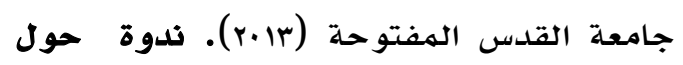

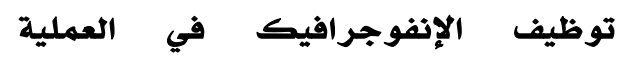

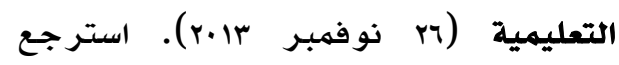

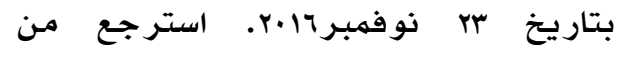
WWW.qou.edu

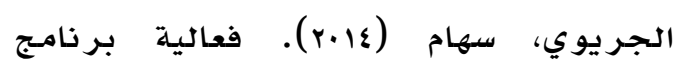
تدريبي مقترح في تنمية مهارات تصميم لونيم الخرائط الذهنية الإكترونية من خلالال

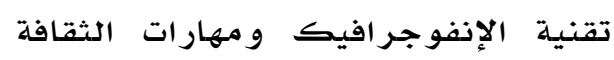

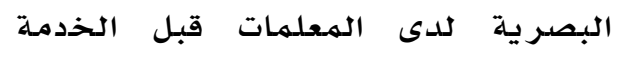

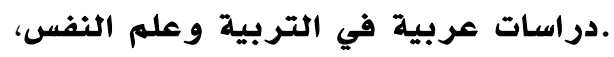
ه

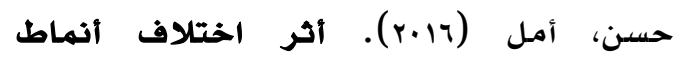

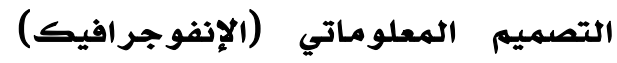
على التحصيل وبقاء أثر التعلم لدى الدئ

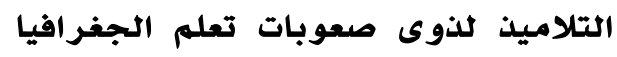
بالمرحلة الإعدادية واتجاههم نحو المادة

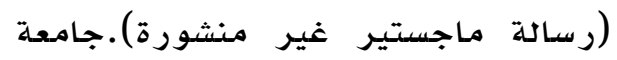
عين شمس، مصر . ماجئر
الفريدة عن صخور عمان، وعززت من الحس

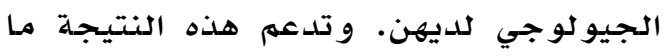
أشارت له بعض الأدبيات حول القيم الجمالية

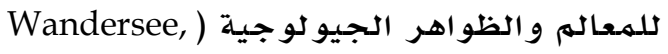

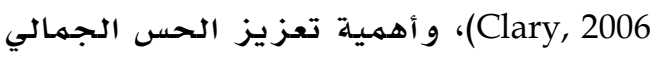

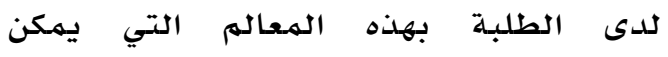

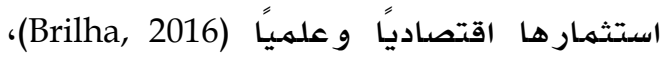
وعلى ضرورة تدريس البعد الحس الجمالي

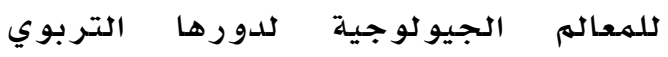
والسياحي ( Kirillova et al., 2014; Warowna ) لدوبري

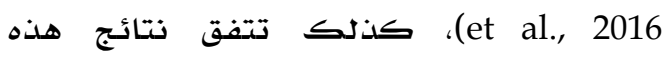

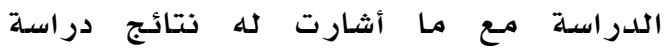
(Kirillova et al., 2014) الحس الجيولوجي في إدراك الطلبة للقدرة الإلهية في خلق تلك المعالم و تشكيلها. التوصيات

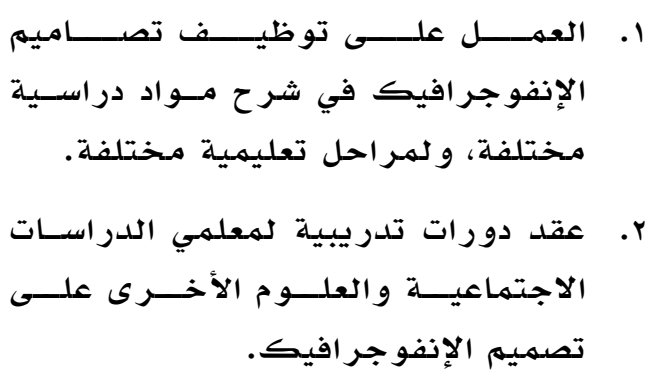

\section{References}

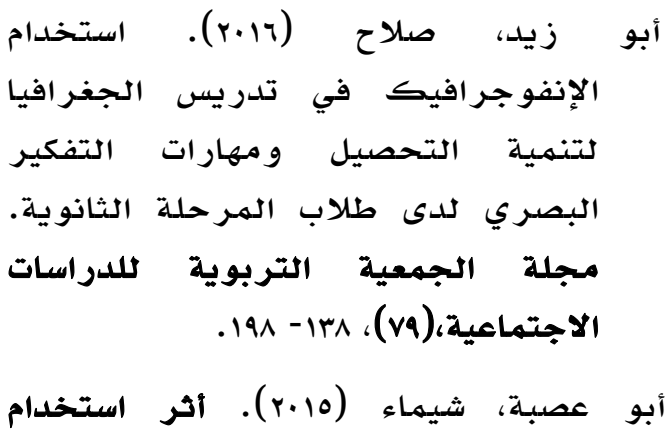




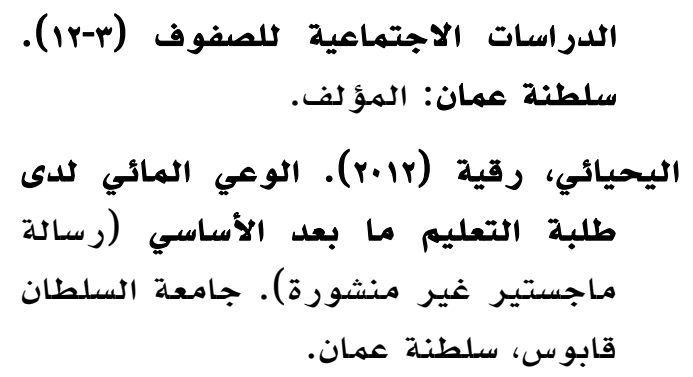

Al Hosni, J. (2016). The power of image in English language teaching. Journal of Teaching English for Specific and Academic Purposes, 4(1), 229-235.

Alshehri, M. A., \& Ebaid, M. (2016). The effectiveness of using interactive infographic at teaching mathematics in elementary school. British Journal of Education, 4(3), 1-8.

Borkin, M. A., Vo, A. A., Bylinskii, Z., Isola, P., Sunkavalli, S., Oliva, A., \& Pfister, H. (2013). What makes a visualization memorable? IEEE Transactions on Visualization and Computer Graphics, 19(12), 2306-2315.

Brilha, J. (2016). Inventory and quantitative assessment of geosites and geodiversity sites: review. Geoheritage, 8(2), 119-134.

Çifçi, T. (2016). Effects of infographics on students achievement and attitude towards geography lessons. Journal of Education and Learning, 5(1), 154-166.

Clary, R. M., \& Wandersee, J. H. (2006). A writing template for probing students' geological sense of place. Science Education Review, 5(2), 51-59.

Damyanov, I., \& Tsankov, N. (2018). The role of infographics for the development of skills for cognitive modeling in education. International Journal of Emerging Technologies in Learning (iJET), 13(1), 82-92.

Dowling, R. K. (2011). Geotourism's global growth. Geoheritage, 3(1), 1-13.

Holsanova, J., Holmberg, N., \& Holmqvist, K. (2009). Reading information graphics: The role of spatial contiguity and dual attentional guidance. Applied Cognitive Psychology: The Official Journal of the Society for Applied Research in Memory and Cognition, 23(9), 1215-1226.

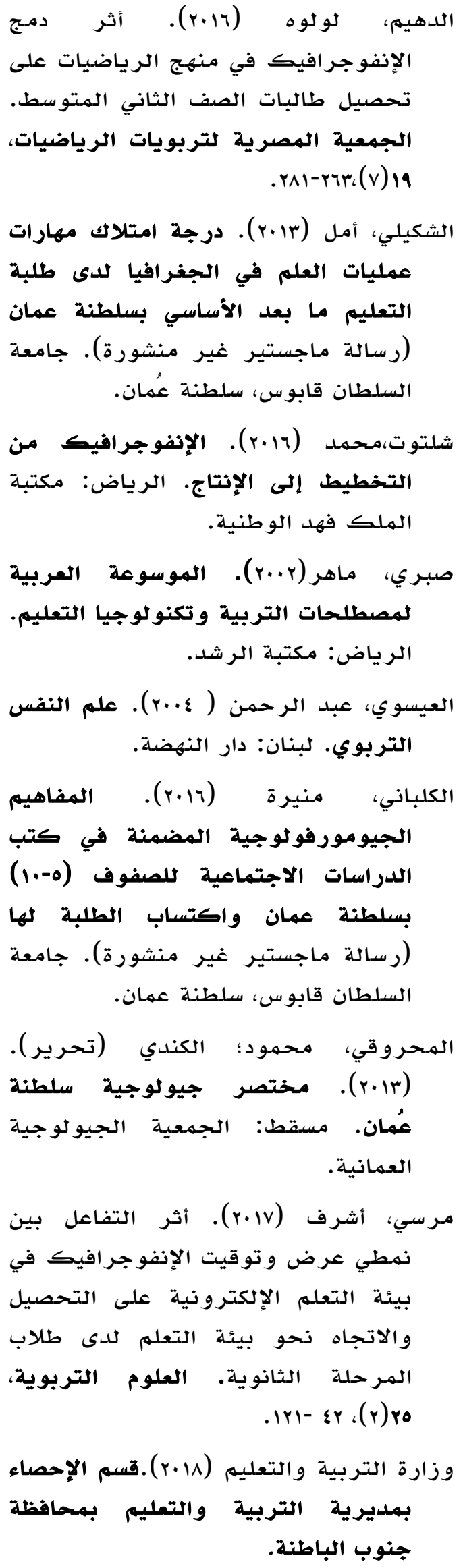

وزارة التربية و التعليم (r..r). وثيقة منهج 
Justin Beegel, M. B. A. (2014). Infographics for dummies . John Wiley \& Sons.

Kirillova, K., Fu, X., Lehto, X., \& Cai, L. (2014). What makes a destination beautiful? Dimensions of tourist aesthetic judgment. Tourism Management, 42, 282-293.

Krauss, J. (2012). More than words can say infographics. Learning and leading with technology, 39(5), 10-14.

Krum, R. (2013). Cool infographics: Effective communication with data visualization and design. Canada: John Wiley \& Sons.

McCue, T. (2013). Why infographics rule. Retrieved March, 5, 2019 from http://www.forbes. com.

Öztürk, M. K. (2002). The importance and usage of educational technology devices and materials in geography teaching in high schools. Hacettepe University Jounal of Education, 22, 126129.

Ruban, D. A. (2015). Geotourism-A geographical review of the literature. Tourism Management Perspectives, 15, 1-15.

Smiciklas, M. (2012). The power of infographics: Using pictures to communicate and connect with your audiences. New Jersey :Que Publishing.

Warowna, J., Zgłobicki, W., KołodyńskaGawrysiak, R., Gajek, G., Gawrysiak, L., \& Telecka, M. (2016). Geotourist values of loess geoheritage within the planned Geopark Małopolska Vistula River Gap, E Poland. Quaternary International, 399, 46-57. 